\title{
Attribution of forced decadal climate change in coupled and uncoupled ocean- atmosphere model experiments
}

Article

Published Version

Dong, B., Sutton, R. T., Shaffrey, L. and Klingaman, N. P. (2017) Attribution of forced decadal climate change in coupled and uncoupled ocean-atmosphere model experiments. Journal of Climate, 30 (16). pp. 6203-6223. ISSN 1520-0442 doi: https://doi.org/10.1175/JCLI-D-16-0578.1 Available at https://centaur.reading.ac.uk/70772/

It is advisable to refer to the publisher's version if you intend to cite from the work. See Guidance on citing.

Published version at: http://journals.ametsoc.org/doi/abs/10.1175/JCLI-D-16-0578.1

To link to this article DOI: http://dx.doi.org/10.1175/JCLI-D-16-0578.1

Publisher: American Meteorological Society

All outputs in CentAUR are protected by Intellectual Property Rights law, including copyright law. Copyright and IPR is retained by the creators or other copyright holders. Terms and conditions for use of this material are defined in the End User Agreement.

www.reading.ac.uk/centaur 
Central Archive at the University of Reading

Reading's research outputs online 


\title{
${ }^{\partial}$ Attribution of Forced Decadal Climate Change in Coupled and Uncoupled Ocean-Atmosphere Model Experiments
}

\author{
Buwen Dong, Rowan T. Sutton, Len Shaffrey, And Nicholas P. Klingaman \\ National Centre for Atmospheric Science, Department of Meteorology, University of Reading, Reading, United Kingdom
}

(Manuscript received 5 August 2016, in final form 31 March 2017)

\begin{abstract}
There is still no consensus about the best methodology for attributing observed changes in climate or climate events. One widely used approach relies on experiments in which the time periods of interest are simulated using an atmospheric general circulation model (AGCM) forced by prescribed sea surface temperatures (SSTs), with and without estimated anthropogenic influences. A potential limitation of such experiments is the lack of explicit atmosphere-ocean coupling; therefore a key question is whether the attribution statements derived from such studies are in fact robust. In this research the authors have carried out climate model experiments to test attribution conclusions in a situation where the answer is known-a so-called perfect model approach. The study involves comparing attribution conclusions for decadal changes derived from experiments with a coupled climate model (specifically an AGCM coupled to an ocean mixed-layer model) with conclusions derived from parallel experiments with the same AGCM forced by SSTs derived from the coupled model simulations. Results indicate that attribution conclusions for surface air temperature changes derived from AGCM experiments are generally robust and not sensitive to air-sea coupling. However, changes in seasonal mean and extreme precipitations, and circulation in some regions, show large sensitivity to air-sea coupling, notably in the summer monsoons over East Asia and Australia. Comparison with observed changes indicates that the coupled simulations generally agree better with observations. These results demonstrate that the AGCM-based attribution method has limitations and may lead to erroneous attribution conclusions in some regions for local circulation and mean and extreme precipitation. The coupled mixed-layer model used in this study offers an alternative and, in some respects, superior tool for attribution studies.
\end{abstract}

\section{Introduction}

Weather and climate extreme events can have devastating impacts on human society, the economy, and the infrastructure. Understanding the underlying causes of observed changes in these events is a fundamental step in developing robust climate predictions, providing climate risk assessments, and guiding climate adaptation strategies. While a specific weather and climate extreme event cannot be solely attributed to a single cause, it is still possible to estimate how certain factors, such as the effects of anthropogenic forcings, may have modified the probability and/or contributed to the intensity of the event (e.g., Sun et al. 2014; King et al. 2015a,b, 2016; Rupp et al. 2015; Schaller et al. 2016; Stott et al. 2016).

๑ Denotes content that is immediately available upon publication as open access.

Corresponding author: Buwen Dong, b.dong@reading.ac.uk
There is rich observational evidence that global and continental mean surface temperatures have warmed and that the intensity of hot and cold extremes and the number of heatwaves on global, continental, and subcontinental scales have changed significantly over recent decades (Alexander et al. 2006; Hegerl et al. 2007; Stott et al. 2010; Hegerl and Zwiers 2011; Donat et al. 2013; Lewis and Karoly 2013). Attribution studies have indicated that the effects of anthropogenic forcings are important contributing factors with high confidence for the warming on global and continental scales and have increased the probability of hot extremes and the number of heatwaves, and reduced the probability of the cold extremes (Hegerl et al. 2007; Stott et al. 2010; Hegerl and Zwiers 2011; Christidis et al. 2013, 2015; Perkins et al. 2012; Seneviratne 2012; Bindoff et al. 2013; Lewis and Karoly 2013; Morak et al. 2013; Wen et al. 2013; Sun et al. 2014; Weaver et al. 2014; Black et al. 2015, Fischer and Knutti 2015; Perkins 2015; Dong et al. 2016, 2017; Hansen and Stone 2016; 
King et al. 2015a,b, 2016; National Academies of Sciences, Engineering, and Medicine (NAS) 2016; Stott et al. 2016). However, evidence concerning anthropogenic influences on changes in regional precipitation and the probability of extreme precipitation events is more mixed, since observational and model uncertainties, as well as model errors and large internal variability in precipitation, limit confidence in attribution assessments (Fischer and Knutti 2015; NAS 2016; Sarojini et al. 2016; Schaller et al. 2016; Stott et al. 2016).

Despite the rapid development in science of weather and climate event attributions in recent years (NAS 2016; Stott et al. 2016), there is still no consensus about the best methodology for attribution. One widely used approach to climate event attribution relies on experiments in which the time periods of interest are simulated using an atmospheric general circulation model (AGCM) forced by prescribed sea surface temperatures (SSTs), with and without anthropogenic influences (e.g., Pall et al. 2011; Christidis et al. 2013, 2015; Imada et al. 2014; Kamae et al. 2014; Min et al. 2014; Shiogama et al. 2014; King et al. 2015a,b; Rupp et al. 2015; Schaller et al. 2016). A potential limitation of these experiments is the lack of explicit atmosphere-ocean coupling.

This limitation may be important, as studies have shown that air-sea coupling improves the simulation of mean climate over tropics and improves monsoon prediction (e.g., Hendon et al. 2012; Zhu and Shukla 2013). Hirons et al. (2015) found that air-sea coupling alters tropical precipitation biases, even when the AGCM and coupled model have the same SST climatology. Many studies have shown that coupling improves the propagation of, and spectral power associated with, the Madden-Julian oscillation (DeMott et al. 2015, and references therein). The lack of air-sea coupling in AGCMs causes an inconsistency in surface energy fluxes and can limit a model's ability to accurately simulate natural climate variability (e.g., Barsugli and Battisti 1998; Wang et al. 2005; He and Soden 2016).

The evidence that air-sea coupling is important for the simulation of climate and climate variability motivates us to investigate the implications for climate attribution studies. In particular, we seek to explore whether attribution conclusions obtained from AGCM experiments are in fact robust for externally forced decadal changes. Our approach is to compare attribution conclusions derived from experiments with a coupled climate model with conclusions derived from parallel experiments with the same AGCM forced by SSTs taken from the coupled model experiments. The AGCM and coupled model simulations are forced with consistent boundary conditions and radiative forcing and thereby permit us to assess the importance of air-sea coupling for attribution conclusions. The structure of the paper is as follows: in section 2, the model and experiments are described briefly. Section 3 presents an analysis of surface temperature changes. Section 4 focuses on changes in circulation and precipitation. Section 5 elucidates the physical processes involved in the regional precipitation changes simulated over tropical monsoon regions. Finally, conclusions are given in section 6 .

\section{Model and model experiment design}

\section{a. The MetUM-GOML1 model}

The model used is the Met Office Unified Model Global Ocean Mixed Layer (MetUM-GOML1) model, documented in Hirons et al. (2015). The coupled modeling framework comprises the Met Office Unified Model (MetUM) Global Atmosphere, version 3 (Hewitt et al. 2011; Walters et al. 2011) coupled to the MultiColumn $K$ Profile Parameterization (MC-KPP) mixedlayer ocean model via the Ocean Atmosphere Sea Ice Soil (OASIS) coupler (Valcke et al. 2003) with a 3-h coupling frequency. The latitudinal domain of the airsea coupling is limited by the maximum extent of a seasonally varying sea ice climatology (Fig. 2 of Hirons et al. 2015). In the uncoupled region of MetUMGOML1, the atmosphere is forced by the repeating mean annual cycle of SST and sea ice extent (SIE) from the Met Office HadISST dataset (Rayner et al. 2003). MC-KPP is run as a two-dimensional matrix of onedimensional water columns, with one column below each AGCM grid point that is wholly or partially ocean. Each MC-KPP column has 100 levels within a 1000-m column. The vertical discretization allows very highresolution (approximately $1 \mathrm{~m}$ ) in the upper ocean. Vertical mixing in MC-KPP is parameterized using the KPP scheme of Large et al. (1994). Since MC-KPP simulates only vertical mixing and does not include ocean dynamics, climatological seasonal cycles of depthvarying temperature and salinity corrections are prescribed to represent the mean ocean advection and account for biases in atmospheric surface fluxes. The computation of these corrections is described below. More detailed documentation of the model is given in Hirons et al. (2015).

\section{b. Experiments}

The experiments are summarized in Table 1. A 12-yr MetUM-GOML1 relaxation experiment was performed in which the MC-KPP profiles of temperature and salinity were relaxed to a present day (PD; 1994-2011) ocean temperature and salinity climatology derived from the Met Office ocean analysis (Smith and Murphy 
TABLE 1 . Summary of numerical experiments.

\begin{tabular}{|c|c|c|c|}
\hline & Expt & Ocean & Radiative forcings \\
\hline R0 & Relaxation run & $\begin{array}{l}\text { Relaxation to "present day" (PD, 1994-2011) } \\
\text { mean 3D ocean temperature and salinity to } \\
\text { diagnose climatological temperature and } \\
\text { salinity tendencies }\end{array}$ & $\begin{array}{l}\text { Time mean PD greenhouse gases (GHGs) over } \\
\text { 1994-2011 and time mean anthropogenic } \\
\text { aerosol (AA) precursor emissions over 1994- } \\
2010 \text { with AA after } 2006 \text { from the RCP4.5 } \\
\text { scenario (Lamarque et al. 2010, 2011) }\end{array}$ \\
\hline CPD & $\begin{array}{l}\text { Coupled PD (1994-2011) } \\
\text { experiment }\end{array}$ & $\begin{array}{l}\text { Climatological temperature and salinity } \\
\text { tendencies from experiment } \mathrm{R} 0\end{array}$ & $\begin{array}{l}\text { Time mean PD GHGs over 1994-2011and time } \\
\text { mean AA precursor emissions over 1994-2010 }\end{array}$ \\
\hline CEP & $\begin{array}{l}\text { Coupled "early period" } \\
\quad(\text { EP; 1964-81) experiment }\end{array}$ & $\begin{array}{l}\text { Climatological temperature and salinity } \\
\text { tendencies from experiment } \mathrm{R} 0\end{array}$ & $\begin{array}{l}\text { Time mean EP GHGs over } 1964-81 \text { and time } \\
\text { mean AA precursor emissions over } 1970-81\end{array}$ \\
\hline APD & AGCM PD experiment & Daily mean SST from CPD & $\begin{array}{l}\text { Time mean PD GHGs over 1994-2011 and time } \\
\text { mean AA precursor emissions over 1994-2010 }\end{array}$ \\
\hline AEP & AGCM EP experiment & $\begin{array}{l}\text { Daily mean SST from CPD - climatological } \\
\text { (CPD - CEP) daily mean SST }\end{array}$ & $\begin{array}{l}\text { Time mean EP GHGs over } 1964-81 \text { and time } \\
\text { mean AA precursor emissions over } 1970-81\end{array}$ \\
\hline
\end{tabular}

2007) with a relaxation time scale of 15 days. The relaxation experiment used PD time mean anthropogenic greenhouse gas (GHG) and anthropogenic aerosol (AA) forcings (R0; Table 1). The AA precursor emissions are from Lamarque et al. (2010, 2011). The daily mean seasonal cycles of ocean temperature and salinity corrections from the coupled relaxation experiment were diagnosed from the last 10 years of this simulation. These corrections were then imposed in free-running coupled present-day (CPD; 1994-2011) and coupled early period (CEP; 1964-81) experiments with no relaxation. These two periods were chosen to avoid years with a strong impact of the volcanic eruptions.

Two atmosphere-only simulations [atmosphere present day (APD) and atmosphere early period (AEP)] were also performed; APD was forced by the daily SSTs from CPD experiment. AEP was forced by daily SSTs from CPD, after subtracting an estimate of the anthropogenic-forcing-induced SST change. Following the procedure used in AGCM-based attribution studies (e.g., Pall et al. 2011; Christidis et al. 2013, 2015; King et al. 2015a,b; Schaller et al. 2016), this estimate was computed from the climatological daily SST difference between CPD and CEP (Table 1). All simulations use the climatological PD SIE from HadISST (Rayner et al. 2003) with a monthly observed zonal mean ozone climatology (Dall'Amico et al. 2010), a constant solar forcing, and a climatological volcanic aerosol forcing (Andres and Kasgnoc 1998). The CPD, CEP, ADP and AEP experiments were run for 50 years each, but only the last 45 years are analyzed. Note that the EP experiments in this study are not a proxy for a natural or counterfactual world, as is common in attribution studies (e.g., Pall et al. 2011; Christidis et al. 2013, 2015; Imada et al. 2014; Kamae et al. 2014; Min et al. 2014; Shiogama et al. 2014; King et al. 2015a,b; Rupp et al. 2015; Schaller et al. 2016). Instead, in this study we assess the impacts of changes in anthropogenic forcing in coupled and uncoupled model frameworks. The impacts of anthropogenic forcing changes (GHG and AA) within the coupled framework are diagnosed by comparing climate variable distributions between experiments CPD and CEP. The impacts of anthropogenic forcing changes within the uncoupled framework are diagnosed by comparing distributions between experiments APD and AEP. Assuming the diurnal cycle of SSTs is not important for the climate response, the difference between the coupled simulations and AGCM simulations is predominantly due to the lack of coupling with the underlying ocean mixed layer, although atmospheric internal variability can also play a role due to finite sample size. Responses to anthropogenic forcing changes in both coupled and uncoupled frameworks can be compared to observed changes between PD and EP and are used to assess the role of changes in anthropogenic forcing in observed changes, and whether air-sea coupling is an important factor.

\section{c. MetUM-GOML1 climatology}

Despite improvements in the representations of physical processes in coupled GCMs, they still have serious systematic errors that challenge the reliability of climate predictions (e.g., Wang et al. 2014). SSTs simulated by CMIP5 models are generally too cold $\left(1^{\circ}-2^{\circ} \mathrm{C}\right)$ in the Northern Hemisphere and too warm $\left(1^{\circ}-2^{\circ} \mathrm{C}\right)$ in the Southern Hemisphere (e.g., Wang et al. 2014). Figures $1 \mathrm{a}$ and $1 \mathrm{~b}$ show the December-February (DJF) and June-August (JJA) SSTs biases for the CPD experiment relative to HadISST. By prescribing the temperature and salinity corrections, mean SST biases in both boreal winter (DJF) and summer (JJA) in the MetUM-GOML1 model are much smaller (typically between $-0.5^{\circ}$ and $0.5^{\circ} \mathrm{C}$ ) than those in CMIP5 models (Wang et al. 2014; Hirons et al. 2015). 
(a) DJF mean SST bias for (1994to2011)

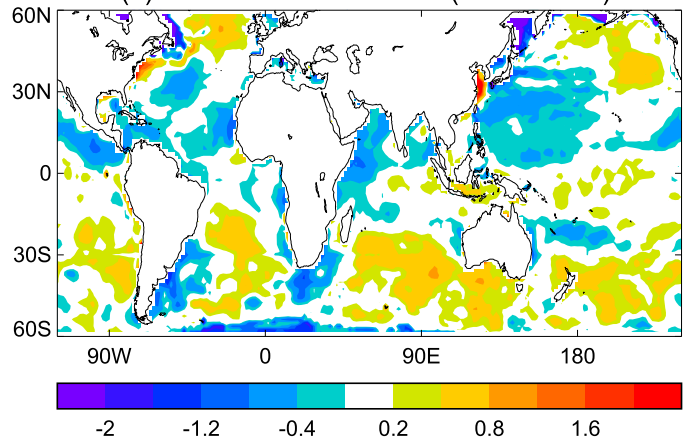

(c) DJF Precipitation (Uncoupled)

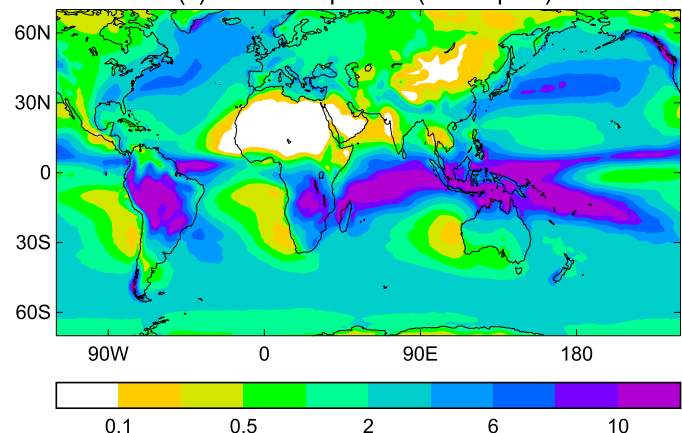

(e) DJF precipitation bias (Uncoupled)

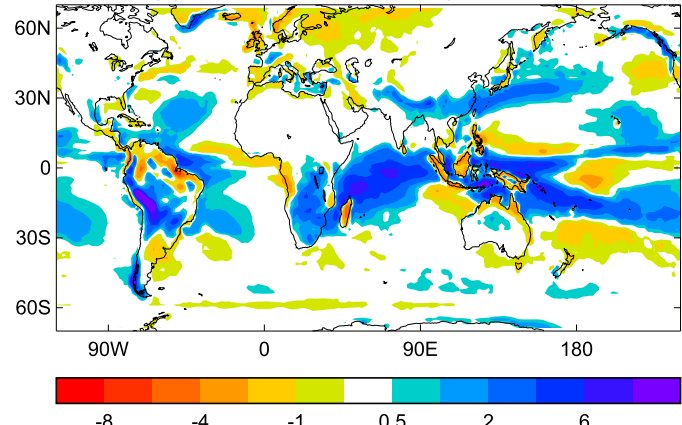

(g) DJF Precipitation change (C-U)

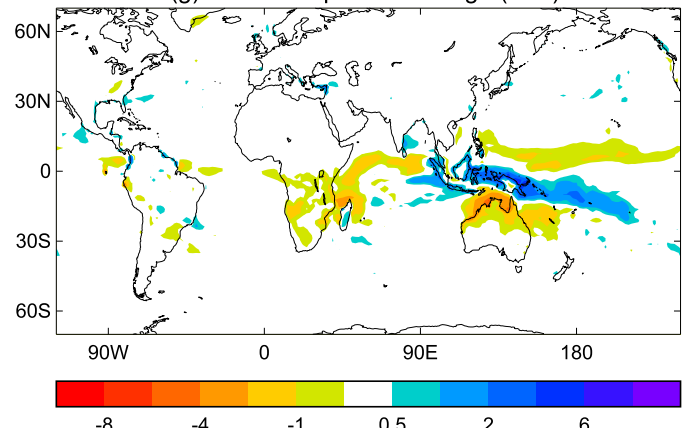

(b) JJA mean SST bias for (1994to2011)

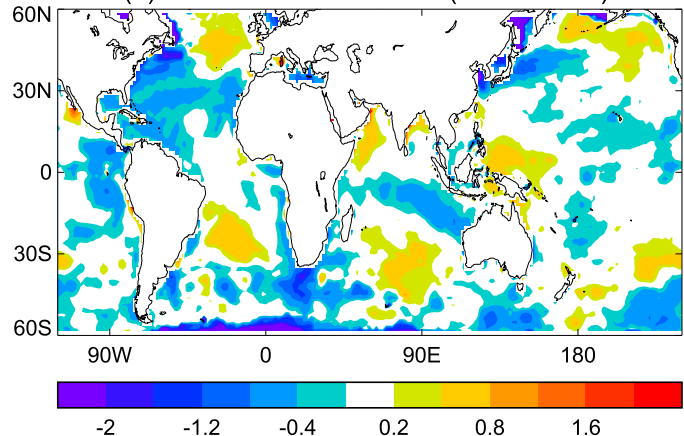

(d) JJA Precipitation (Uncoupled)

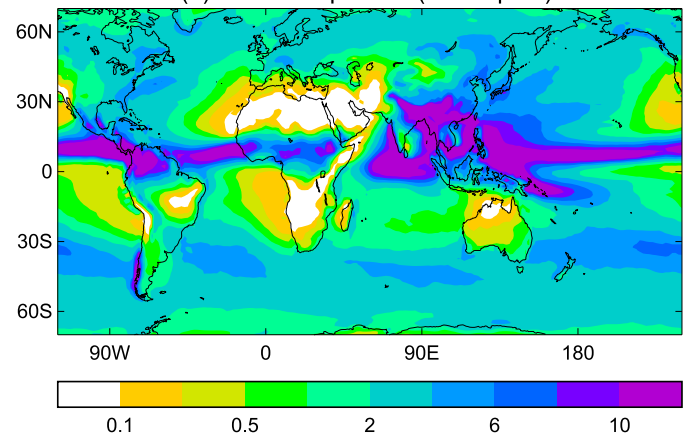

(f) JJA precipitation bias (Uncoupled)

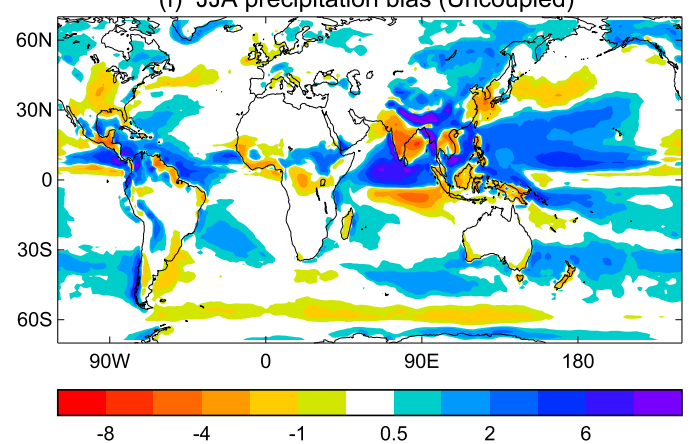

(h) JJA Precipitation change (C-U)

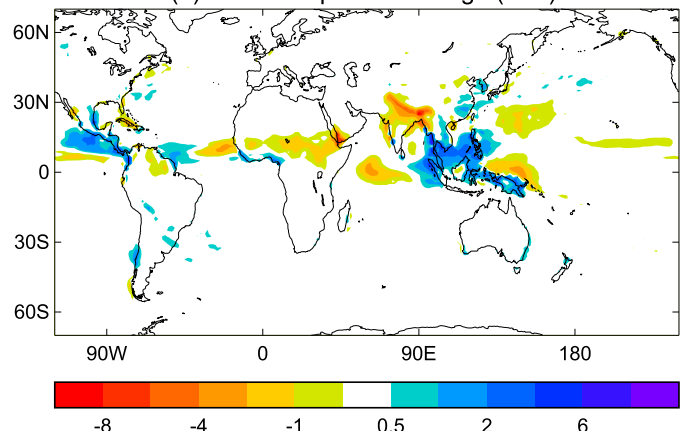

FIG. 1. Sea surface temperature (SST; ${ }^{\circ} \mathrm{C}$ ) bias in the coupled simulation (CPD) (a) for DJF and (b) for JJA relative to HadISST (Rayner et al. 2003). Precipitation $\left(\mathrm{mm} \mathrm{day}^{-1}\right.$ ) in the uncoupled simulation (APD) (c) for DJF and (d) for JJA. (e) DJF and (f) JJA precipitation bias in the uncoupled simulation (APD) relative to GPCP v2.2 (Adler et al. 2003). (g) DJF and (h) JJA precipitation differences between the coupled and uncoupled simulations (CPD-APD). 
(a) DJF Obs. SST change (1994to2011)-(1964to1981)

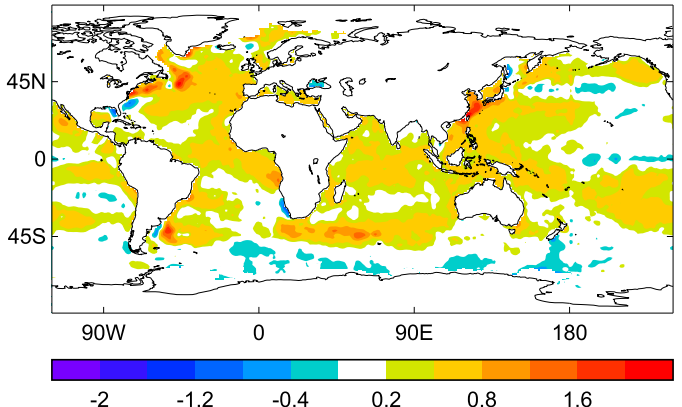

(c) DJF Simulated SST change (Coupled)

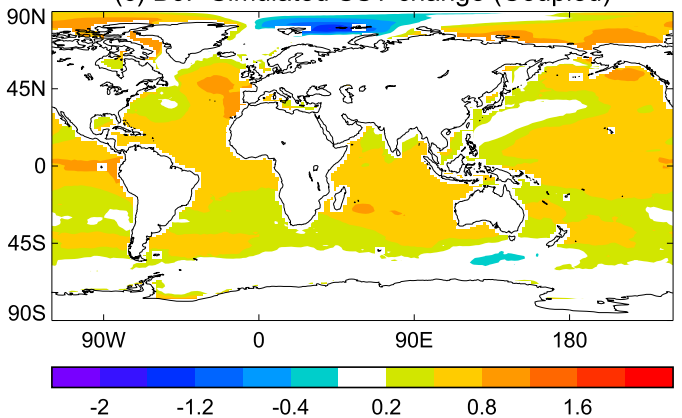

(b) JJA Obs. SST change (1994to2011)-(1964to1981)

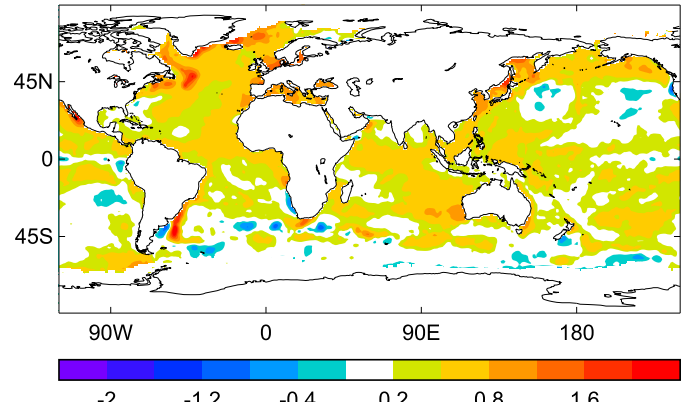

(d) JJA Simulated SST change (Coupled)

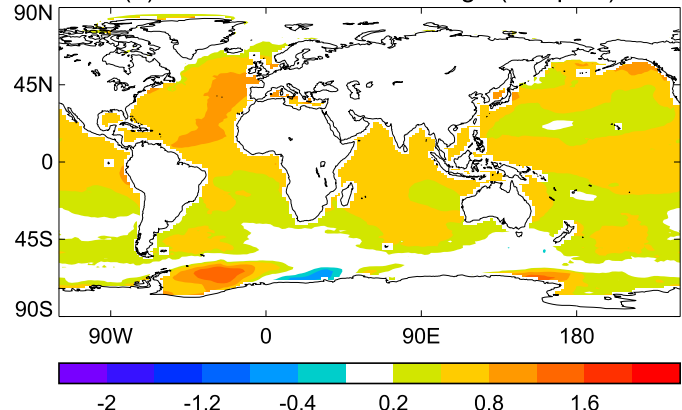

FIG. 2. SST $\left({ }^{\circ} \mathrm{C}\right)$ difference between PD (1994-2011) and EP (1964-81) for (left) DJF and (right) JJA, based on (a),(b) HadISST and (c),(d) MetUM-GOML1 model simulations (CPD-CEP).

Figures 1c and 1d shows the seasonal DJF and JJA precipitation climatologies from the APD experiment, while Figs. 1e and 1f show the DJF and JJA biases of precipitation in APD relative to GPCP. In comparison with the observed data, precipitation from APD is overestimated over the northwest Pacific, the Maritime Continent (MC), and the Indian Ocean in DJF. In JJA, APD exhibits wet biases over the equatorial Indian Ocean (EIO) and western tropical Pacific, and dry biases over the Indian subcontinent, MC islands, eastern China, and the Korean Peninsula (Fig. 1f). These tropical rainfall biases are longstanding errors in the MetUM (e.g., Ringer et al. 2006; Walters et al. 2011) and were also present in CMIP3 models and not much improved in CMIP5 models (Sperber et al. 2013). Relative to APD, in DJF the CPD experiment exhibits very small changes in precipitation over global land (Fig. 1g); changes over the oceans reduce the biases in some regions and increase them elsewhere. In JJA, the precipitation biases over the EIO, MC islands, and eastern China are improved in CPD (Fig. 1h), indicating the importance of air-sea coupling for the simulation of the precipitation climatology over these regions (e.g., Hendon et al. 2012; Zhu and Shukla 2013; Ham et al. 2014). However, coupling clearly does not eliminate the biases in the atmospheric model simulations; for example, there is no improvement in the lack of monsoonal precipitation over the Indian subcontinent (Figs. 1f,h). Although the model shows some large systematic errors in precipitation over the ocean in both DJF and JJA, and over India in JJA, the biases over Australia in DJF and over East Asia in JJA are relatively small. Precipitation responses to changes in anthropogenic forcing in these two regions show large sensitivity to air-sea coupling; understanding the physical processes involved in the different responses is a major focus of this study.

To address whether the model bias in precipitation is sensitive to sampling uncertainty, we performed further analysis by separating the PD 45-yr simulations into two groups of 23 and 22 years, respectively. The results indicate that both the pattern and magnitude of biases, and the changes between the coupled and uncoupled simulations, are very similar in the two groups (not shown), and they are also very similar to those based on the full 45-yr simulations. Thus the impact of sampling uncertainty is small.

\section{Sea surface temperature and surface air temperature responses to changes in anthropogenic forcing}

In this section, we investigate the magnitude and pattern of SST changes resulting from changes in anthropogenic forcing in MetUM-GOML1 between the PD and EP periods. Shown in Fig. 2 are the SST changes 
between the PD and EP in observations and MetUMGOML1. Observations show a relatively large warming $\left(0.4^{\circ}-0.8^{\circ} \mathrm{C}\right)$ over the North and tropical Atlantic, the Indian Ocean, and the western tropical Pacific in both seasons. Note that the changes in observations between the two periods are not purely due to changes in anthropogenic forcing: they are a combination of forced changes and internally driven decadal variability. There is no perfect method to remove the contribution from internal variability but, following the suggestion of a reviewer, we investigated subtracting the contribution from the internally driven components of the observed Atlantic multidecadal variability (AMV) and interdecadal Pacific variability (IPV), following the Decadal Climate Prediction Project (DCPP-C) protocol (e.g., Boer et al. 2016). The resulting residual SST change patterns (not shown) are similar to Figs. $2 a$ and $2 b$, suggesting that these changes are, to a large degree, externally forced. This conclusion is consistent with the Intergovernmental Panel on Climate Change (IPCC) conclusion that the warming of the upper several hundred meters of ocean during the second half of the twentieth century was "likely" to have been caused by anthropogenic forcing (Hegerl et al. 2007; Bindoff et al. 2013).

MetUM-GOML1 simulates positive SST anomalies in all ocean basins in response to changes in anthropogenic forcing, with a relatively large warming over the northern and tropical Atlantic, the Indian Ocean, and the tropical Pacific in both seasons. Many features of these simulated changes are similar to the observed changes. However, the model simulated warming over the tropical central and eastern Pacific is about $0.2^{\circ}-0.4^{\circ} \mathrm{C}$ warmer than that in observations while the simulated warming over the high latitudes of the North Atlantic, where ocean dynamics played an important role in recent SST changes (e.g., Robson et al. 2012; McGregor et al. 2014) is weaker than that in observations. Large differences between the modelsimulated SST changes and observations are also found over the western North Pacific in DJF, where the model response is smaller than the observed warming of $0.4^{\circ}-$ $0.8^{\circ} \mathrm{C}$ (Figs. 2a,c). Despite these differences, the similarity of the large-scale pattern of anomalous SST distributions between MetUM-GOML1 simulated changes and observed SST changes, even though MC-KPP does not include ocean dynamics, confirms that observed changes between two periods were substantially caused by changes in anthropogenic forcing. We note again that some differences between the simulated and observed patterns are expected due to the (poorly known) contribution of internal variability to the observed changes.

The spatial patterns of changes in surface air temperature (SAT) over global land, based on CRUTS3.21 (Harris et al. 2014) and in model simulations, are illustrated in
Fig. 3. Observations show that the largest warming $\left(1.0^{\circ}-\right.$ $2.0^{\circ} \mathrm{C}$ ) occurred over the $\mathrm{NH}$ continent in DJF. Large warming $\left(1.0^{\circ}-1.5^{\circ} \mathrm{C}\right)$ also occurred over Europe, Africa, and northeast Asia in JJA (e.g., van Oldenborgh et al. 2009; Chen and Lu 2014; Dong et al. 2016, 2017). MetUMGOML1 simulates these features, although the simulated temperature changes are spatially more homogenous. In many aspects, the SAT changes in both JJA and DJF in response to changes in anthropogenic forcing in the uncoupled experiments are similar to those in the coupled experiments, except for local changes over the eastern United States in DJF. Separating the 45-yr simulations into two chunks of 23 and 22 years (not shown) gives patterns of SAT responses similar to those based on the full $45-\mathrm{yr}$ simulations, indicating robust responses to changes in anthropogenic forcing.

To quantify changes in extreme temperatures over land, the spatially aggregated probability density function (PDF) of anomalous SAT distributions for the early period (EP) and present day in both DJF and JJA are calculated (e.g., Fischer and Knutti 2014). First, the seasonal SAT anomaly in EP and PD at each land grid point is calculated relative to the climatology of EP for both observations and model simulations. Then, the local seasonal SAT anomaly in both observations and model simulations are normalized by the corresponding standard deviation of interannual variability in EP. By doing so, the systematic bias in local seasonal mean SAT and interannual variability for EP simulations is masked out. Third, the grid point-scale anomalies are then globally aggregated into a spatial PDF, which quantifies the land fraction exhibiting a certain change (measured in standard deviations $\sigma$ of SAT interannual variability).

The resulting spatially aggregated PDFs for observations, coupled, and uncoupled model simulations in DJF and JJA are shown in Fig. 4 for the Northern Hemisphere $(\mathrm{NH})$ and in Fig. 5 for the Southern Hemisphere (SH). For the observations, the land fraction affected by seasonal hot extremes increases and the land fraction affected by cold extremes decreases in both seasons for both hemispheres, with the largest changes occurring in boreal summer for $\mathrm{NH}$. Land fraction changes of SAT anomalies in DJF for the NH show a shift to warmer temperatures driven by a change in the mean temperature, without much change in variability (Fig. 4a), with the land fraction of very warm winters $(>2 \sigma)$ increased 15-fold from EP to PD. Land fraction changes of SAT in JJA for the NH and in both seasons for the SH shows both a shift in the mean and an increased variability with hot and very hot SAT (Figs. 4b and $5 \mathrm{a}, \mathrm{b})$. The land fraction in JJA for NH increases 25 -fold for hot summers $(>2 \sigma)$ from EP to PD. Both coupled and uncoupled simulations demonstrate very similar changes to those seen in observations (Figs. 4 and 5). We have also analyzed SAT changes in observations based on 


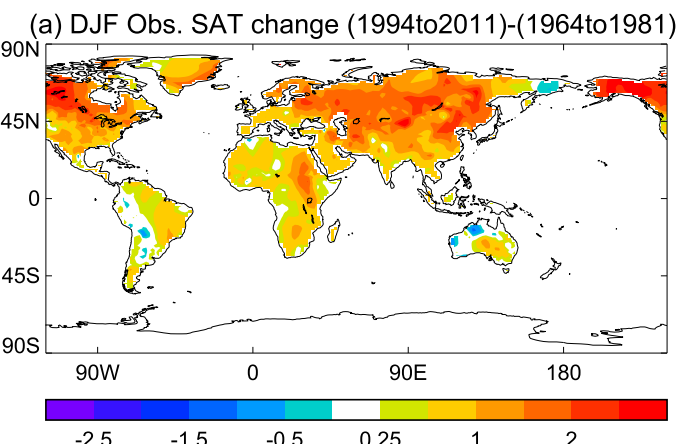

(c) DJF Simulated SAT change (Coupled)

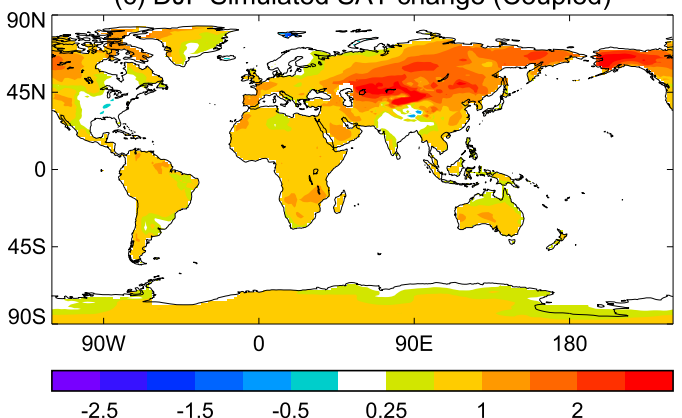

(e) DJF Simulated SAT change (Uncoupled)

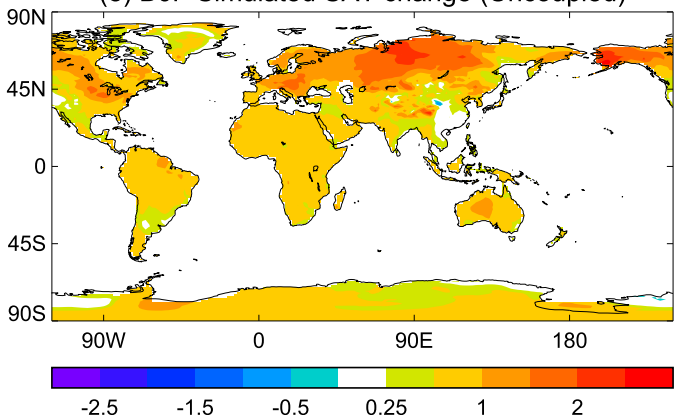

(b) JJA Obs. SAT change (1994to2011)-(1964to1981)

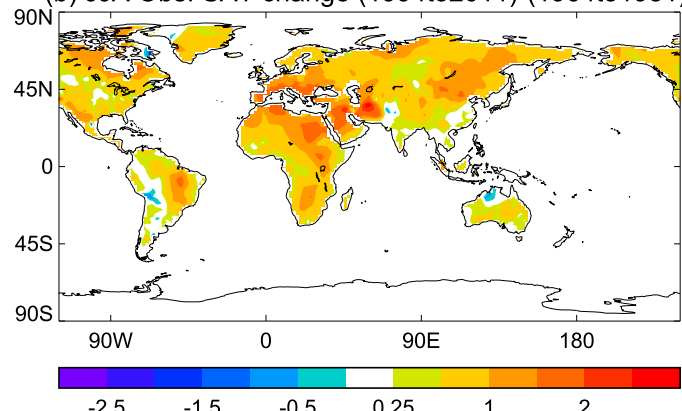

(d) JJA Simulated SAT change (Coupled)

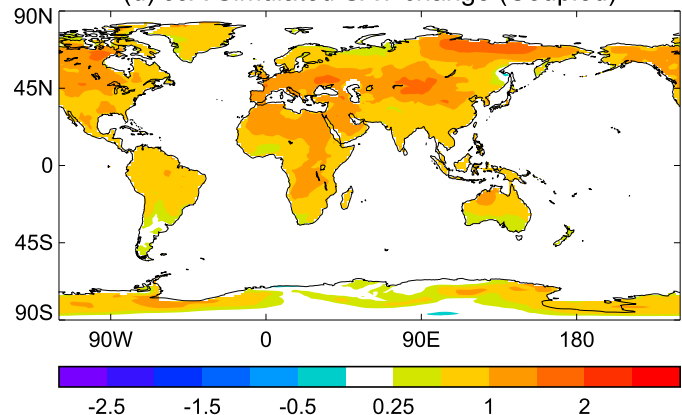

(f) JJA Simulated SAT change (Uncoupled)

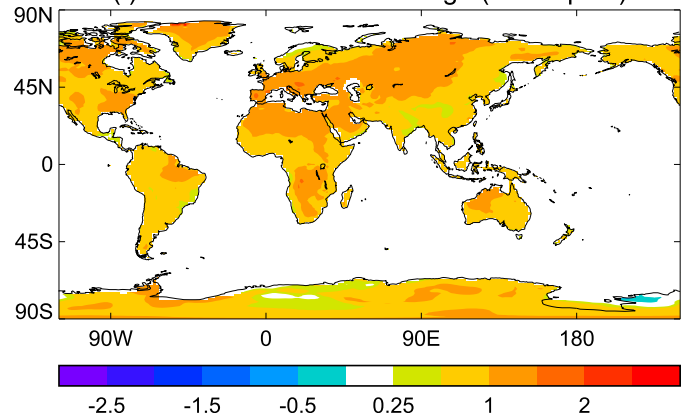

FIG. 3. Surface air temperature $\left({ }^{\circ} \mathrm{C}\right)$ difference between PD (1994-2011) and EP (1964-81) for (left) DJF and (right) JJA, based on (a),(b) CRUTS3.21(Harris et al. 2014), (c),(d) MetUM-GOML1 model simulations (CPDCEP), and (e),(f) uncoupled simulations (APD-AEP).

datasets from the University of Delaware (Legates and Willmott 1990a) and GISTEMP (Hansen et al. 2010). The spatial patterns of changes and the spatially aggregated PDF of anomalous SAT distributions for EP and PD show similar features (not shown) as those demonstrated using the CRUTS3.21 SAT dataset, indicating that the main features of observed changes are robust and not sensitive to the particular dataset used. The similarity between the observed changes in SAT and those in the model simulations suggests that observed changes from EP to PD were likely due to changes in anthropogenic forcing. This is consistent with recent studies (e.g., Christidis et al. 2012; Knutson et al. 2013; Jones et al. 2013), which concluded that it is likely that anthropogenic forcing has made a substantial contribution to continental warming since 1950s. The increasing land fraction of extremely hot events in boreal summer is consistent with Fischer and Knutti (2014) and Kamae et al. (2014). The results in this study indicate that attribution conclusions for large-scale SAT changes derived from AGCM experiments are generally robust; that is, they are not sensitive to air-sea coupling.

\section{Circulation and precipitation responses}

Figure 6 illustrates the sea level pressure (SLP) changes in DJF and JJA between PD and EP in observations, and the simulated responses to anthropogenic forcing changes in the coupled and uncoupled frameworks. Observations 
(a) Fraction of NH land SAT change in DJF

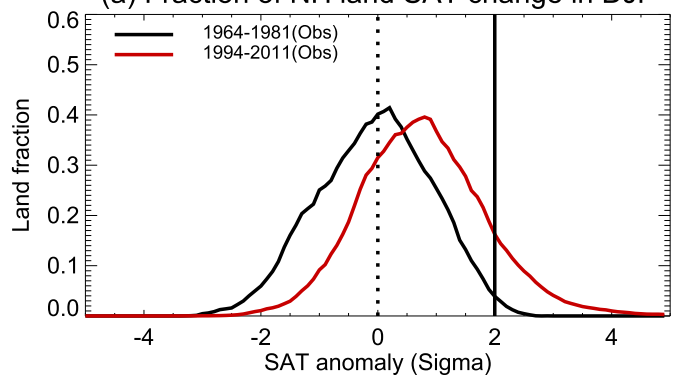

(c) Fraction of NH land SAT change in DJF

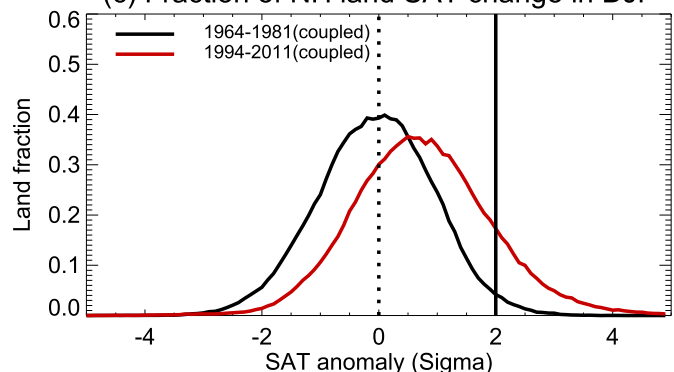

(e) Fraction of NH land SAT change in DJF

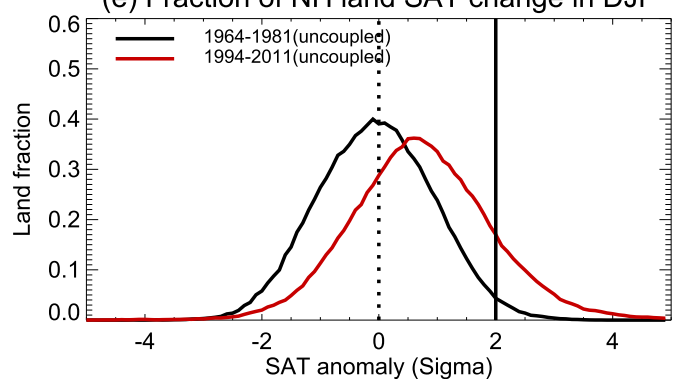

(b) Fraction of NH land SAT change in JJA

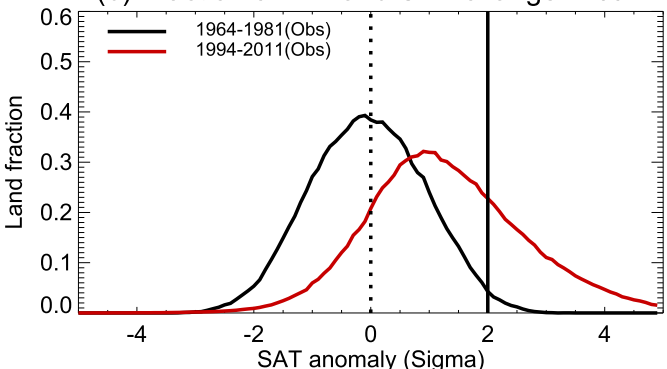

(d) Fraction of NH land SAT change in JJA

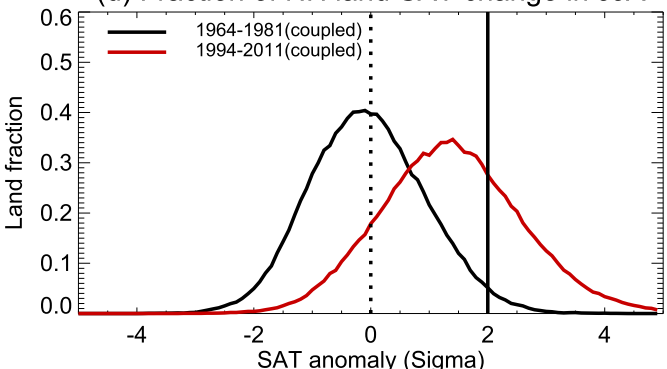

(f) Fraction of NH land SAT change in JJA

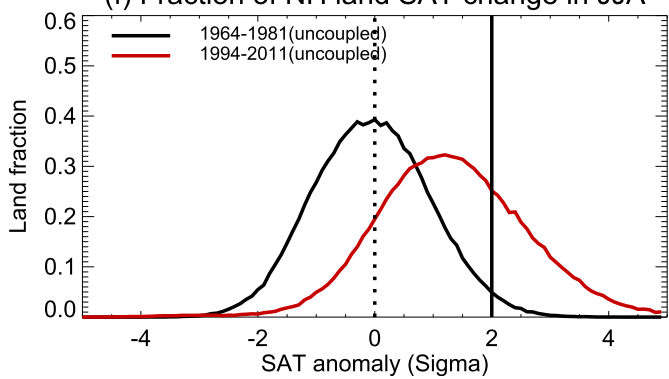

FIG. 4. Spatially aggregated probability density function (PDF) of the Northern Hemisphere (NH) land fraction of normalized SAT anomalies relative to the EP climatology in PD and EP for (left) DJF and (right) JJA. Horizontal axis is in standard deviation of interannual variability and the bin width is $0.1 \sigma$. All PDFs are normalized such that their area integral is unity. Results are based on (a),(b) CRUTS3.21(Harris et al. 2014), (c),(d) MetUMGOML1 model simulations (CPD and CEP), and (e),(f) uncoupled simulations (APD and AEP).

show an increase in SLP over the SH midlatitudes and a decrease over the SH high latitudes in both seasons (Figs. 6a,b). These changes in SLP project onto the positive phase of the southern annular mode (SAM) (e.g., Fyfe et al. 1999). As noted previously, differences between the simulated and observed patterns may be due to the contribution of internal variability, as well as to errors in the prescribed forcing and simulated responses. Note that there is no change in ozone forcing between EP and PD experiments; some previous studies suggested that the change in ozone is the main driver of recent observed SAM changes (e.g., Gillett and Thompson 2003; Shindell and Schmidt 2004; Arblaster and Meehl 2006). Highlatitude changes in $\mathrm{NH}$ project onto the positive phase of the northern annular mode (NAM) in DJF (e.g., Fyfe et al. 1999). The model responses in DJF in both coupled and uncoupled simulations capture the sign (if not the magnitude) of the observed change in the SAM, suggesting a role for increases in GHGs in the SAM response (e.g., Shindell and Schmidt 2004; Arblaster and Meehl 2006), but the pattern of simulated SLP changes in the Northern Hemisphere shows large differences between coupled and uncoupled simulations, and neither shows good agreement with the observations. The global pattern of SLP changes simulated in JJA is more similar between coupled and uncoupled simulations and it is also similar to observed changes.

The simulated precipitation changes over land (excluding the Americas to enable greater focus) in coupled and uncoupled experiments are illustrated in Fig. 7, together with the observed changes, based on the CRUTS3.21 dataset (Harris et al. 2014). We also checked precipitation changes based on the University of Delaware dataset (Legates and Willmott 1990b) and the PREC/L dataset (i.e., precipitation reconstruction over land; Chen et al. 2002). The main features in these other two precipitation 
(a) Fraction of SH land SAT change in DJF

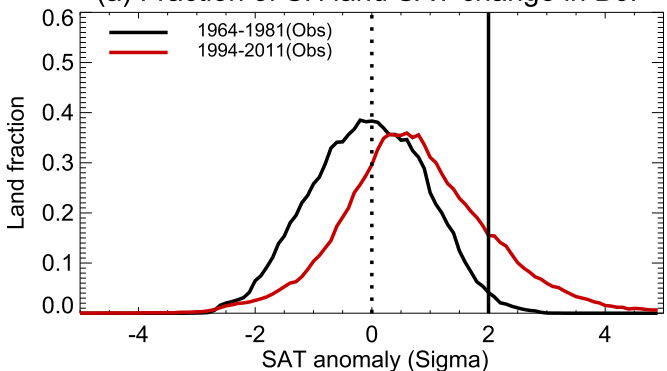

(c) Fraction of $\mathrm{SH}$ land SAT change in DJF

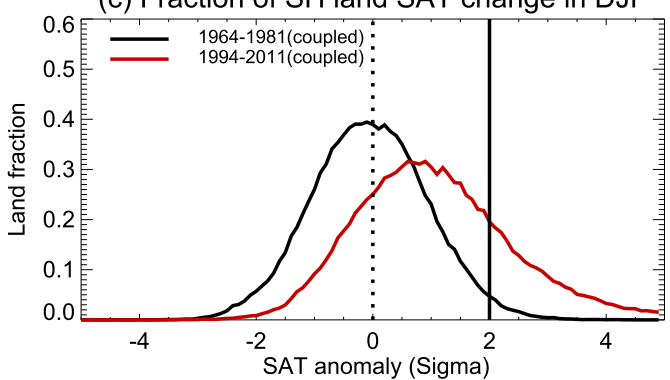

(e) Fraction of SH land SAT change in DJF

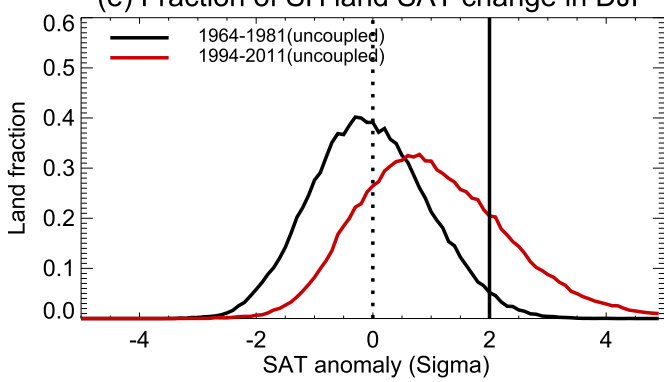

(b) Fraction of SH land SAT change in JJA

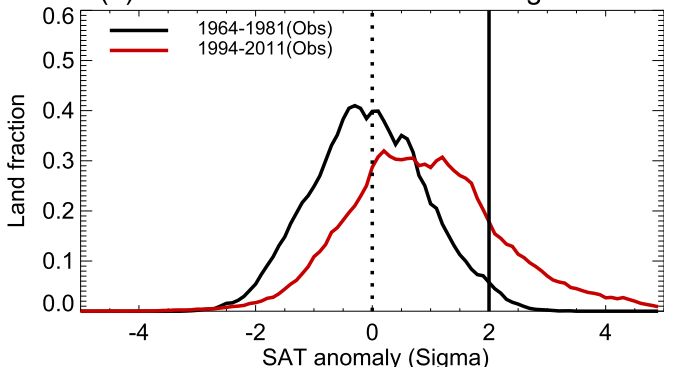

(d) Fraction of SH land SAT change in JJA

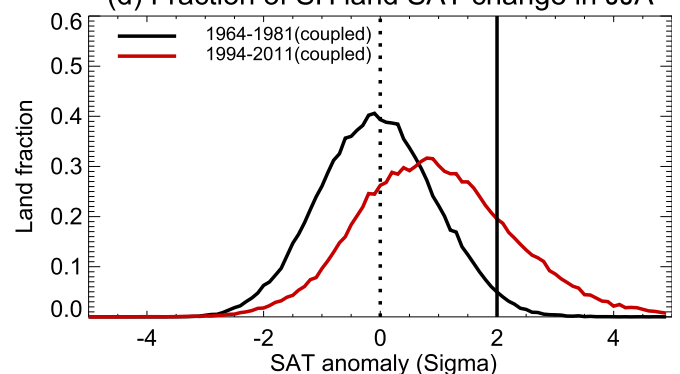

(f) Fraction of SH land SAT change in JJA

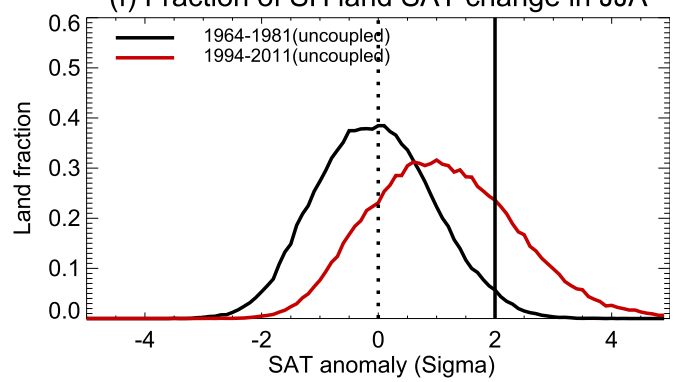

FIG. 5. As in Fig. 4, but for the Southern Hemisphere (SH).

datasets (not shown) are very similar to those shown in Figs. $7 \mathrm{a}$ and $7 \mathrm{~b}$, indicating that the observed changes are robust and not sensitive to the choice of dataset.

In DJF, precipitation changes in both coupled and uncoupled simulations show increased precipitation of about $0.1-0.2 \mathrm{~mm} \mathrm{day}^{-1}$ over northern and central Europe, which is similar to observed changes. However, simulated changes in tropical and subtropical land precipitation in response to changes in anthropogenic forcing show a sensitivity to air-sea coupling. One notable contrast is the increase of precipitation over northwest Australia and the Maritime Continent by 0.4-0.8 $\mathrm{mm} \mathrm{day}^{-1}$ seen in the coupled simulation (Fig. 7a), whereas the uncoupled simulation shows an increase over the eastern part of Australia and relatively small changes over the MC (Fig. 7c). The coupled model response is similar to the observed changes.

In JJA, observed changes in precipitation over Europe indicate a dipole structure with anomalously wet conditions over the north and dry conditions over the south. The model simulated changes over Europe are weak in both the coupled and uncoupled frameworks; they differ from the observed changes. JJA Precipitation changes over Asia, associated with the South Asian and East Asian summer monsoons, show sensitivity to air-sea coupling. The coupled model response features an increase in precipitation over southern China and a decrease over India, and the pattern is similar to the observed changes, whereas the uncoupled responses display changes of the opposite sign (Figs. 7b,d,f).

To address whether differences between the simulations with or without coupling are due to sampling uncertainty, we separated the 45-yr simulations into two chunks of 23 and 22 years, respectively. The results indicate that the conclusions about precipitation changes in the coupled and uncoupled simulations for the two groups (not shown) are similar to the conclusions from the full 45-yr simulations. These analyses confirm that the differences in the response to changes in anthropogenic forcing between the coupled and uncoupled simulations are unlikely due to sampling error.

Figure 8 shows seasonal means of monthly 1-day maximum precipitation (Rx1day) changes between $\mathrm{PD}$ and EP 


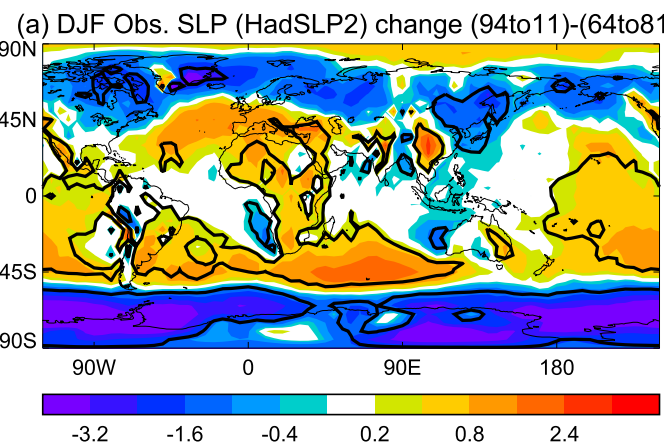

(c) DJF Simulated SLP change (Coupled)

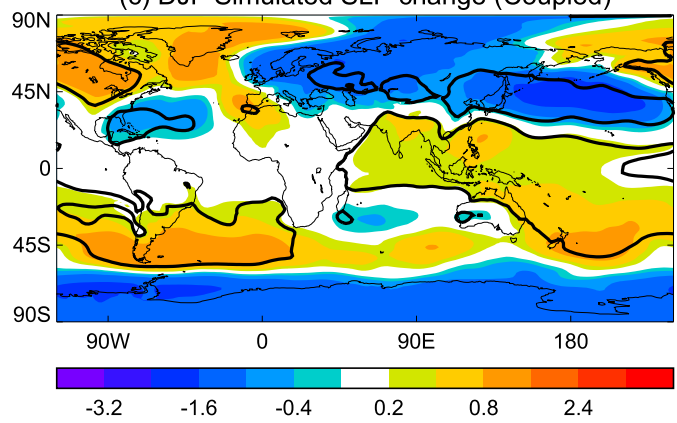

(e) DJF Simulated SLP change (Uncoupled)

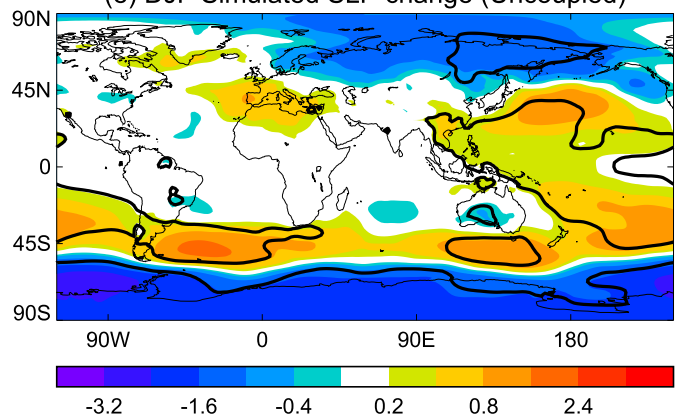

(b) JJA Obs. SLP (HadSLP2) change (94to11)-(64to81)

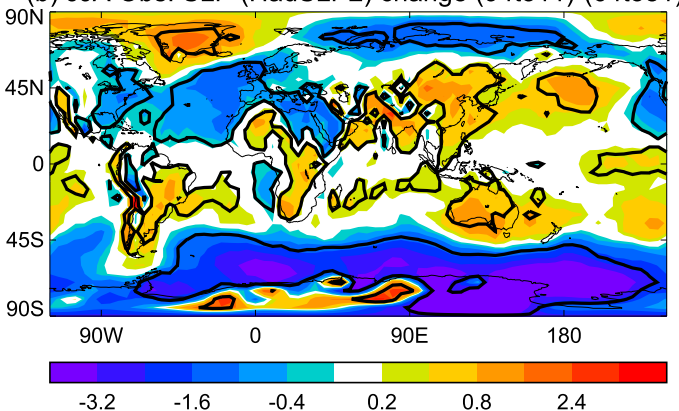

(d) JJA Simulated SLP change (Coupled)

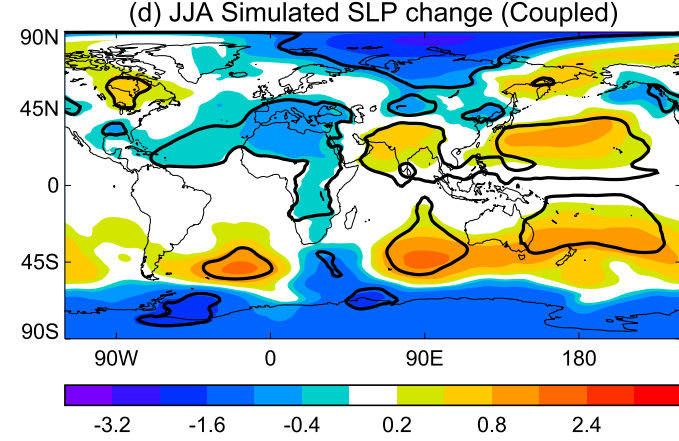

(f) JJA Simulated SLP change (Uncoupled)

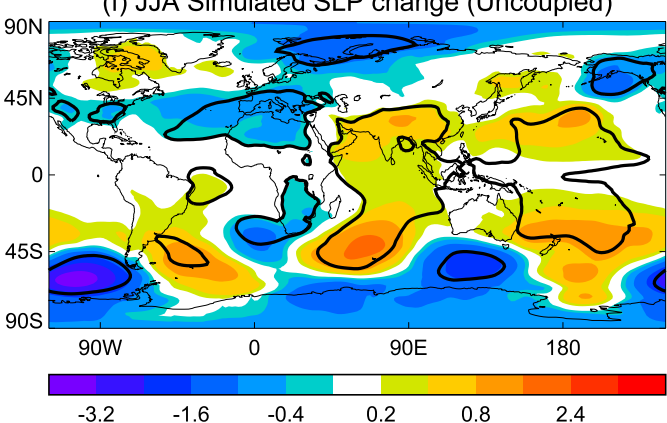

FIG. 6. Sea level pressure (SLP; hPa) difference between PD (1994-2011) and EP (1964-81) for (left) DJF and (right) JJA, based on (a),(b) HadSLP2r (Allan and Ansell 2006), (c),(d) MetUM-GOML1 model simulations (CPD-CEP), and (e),(f) uncoupled simulations (APD-AEP). Thick black lines highlight regions where the changes are statistically significant at the $90 \%$ confidence level based on a two-tailed Student's $t$ test.

in the coupled and uncoupled simulations. The coupled model response shows an increase of extreme precipitation over northwest Australia in DJF, whereas the uncoupled response shows a decrease (Figs. 8a,c). The coupled model response features an increase in extreme precipitation over southern China in JJA and a decrease over northern China, while the uncoupled response shows an opposite change (Figs. 8b,d). Many features are similar to those seen in the seasonal mean precipitation changes, suggesting that some similar mechanisms may be involved.

These results demonstrate that air-sea interactions can play an important role for regional seasonal precipitation and extreme precipitation responses to changes in anthropogenic forcing, especially for regions where summer monsoon flows play a central role in the generation of precipitation. The mechanisms responsible for this sensitivity of local precipitation responses to air-sea coupling will be elucidated in the next section.

\section{Understanding different responses of precipitation over tropical monsoon regions in coupled and uncoupled frameworks}

\section{a. East Asian summer monsoon response}

In this section, the processes responsible for the contrasting precipitation responses in the coupled and 
(a) DJF Obs. Pr (CRUTS3.21) change (94to11)-(64to81)

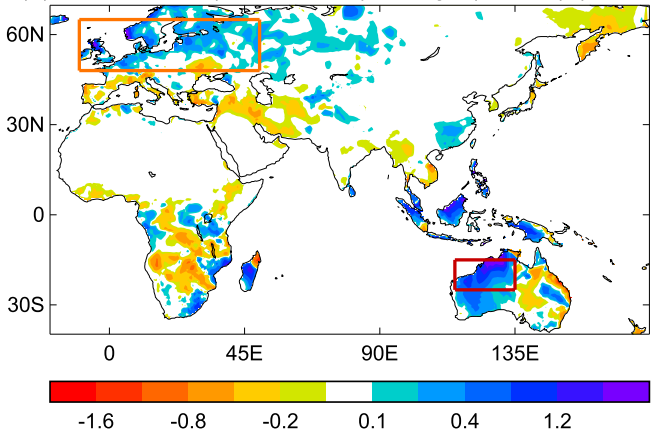

(c) DJF Simulated Pr change (Coupled)

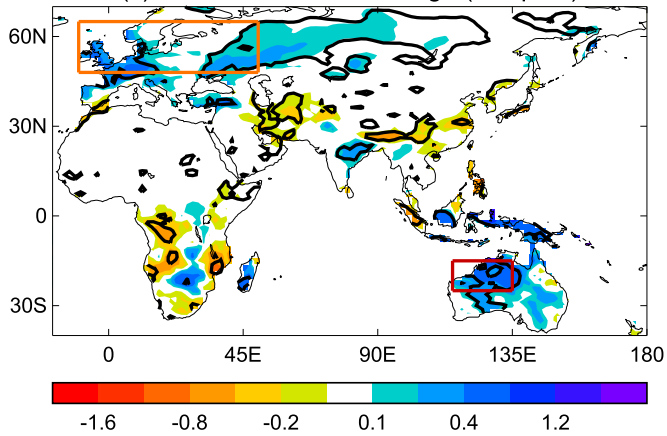

(e) DJF Simulated Pr change (Uncoupled)

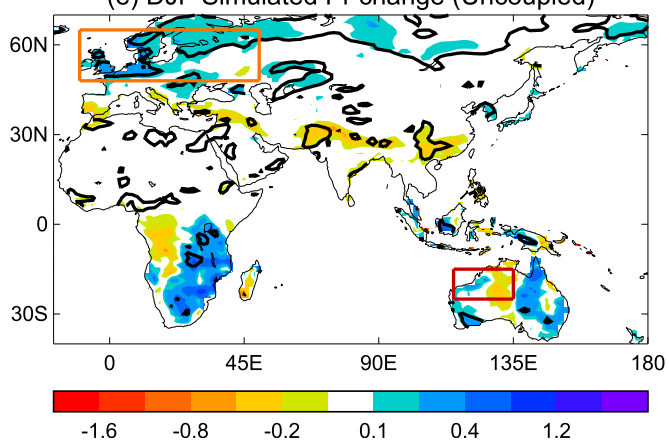

(b) JJA Obs. Pr (CRUTS3.21) change (94to11)-(64to81)

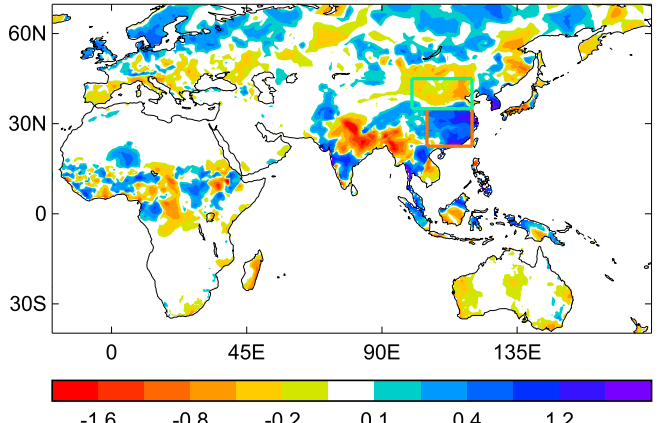

(d) JJA Simulated Pr change (Coupled)

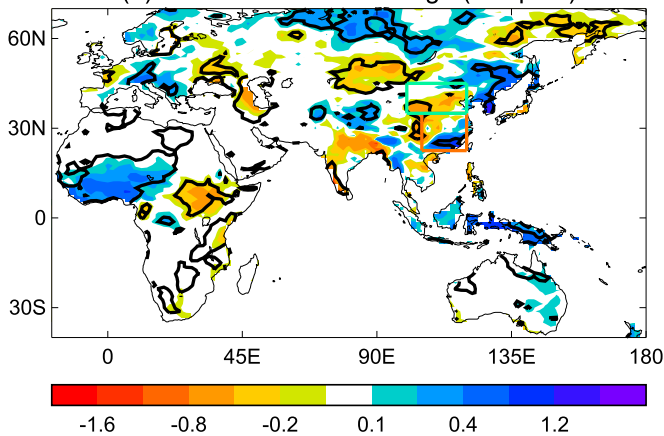

(f) JJA Simulated Pr change (Uncoupled)

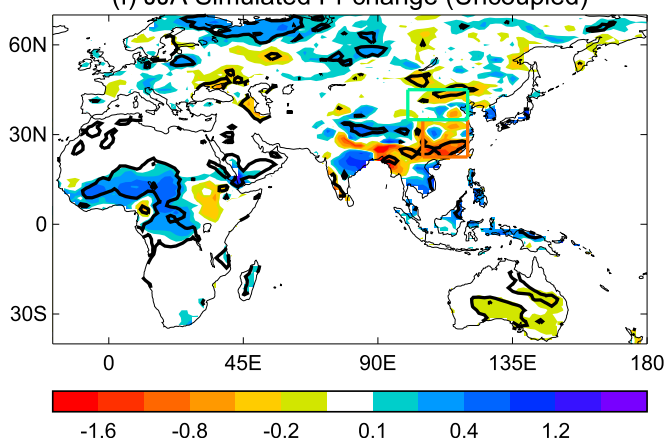

FIG. 7. Precipitation ( $\mathrm{mm} \mathrm{day}^{-1}$ ) difference between PD (1994-2011) and EP (1964-81) for (left) DJF and (right) JJA, for (a),(b) observed changes based on CRUTS3.21, (c),(d) MetUM-GOML1 model simulations (CPD and CEP), and (e),(f) uncoupled simulations (APD and AEP). Color boxes highlight regions where changes in precipitation are discussed in detail in text.

uncoupled models over East Asia in JJA are investigated. Illustrated in Fig. 9 are the observed changes for some key variables, as well as the responses to anthropogenic forcing changes in coupled and uncoupled simulations over East Asia and adjacent regions. Observations show a relatively large warming throughout the warm pool region in the tropical Indian Ocean, South China Sea (SCS), and western tropical Pacific (Figs. 2b and 9a). Generally, these SST changes are simulated in MetUM-GOML1, although the simulated warming extends too far into the tropical central and eastern Pacific (Figs. 2d and 9d). The observed circulation changes are characterized by positive SLP anomalies $(0.8-1.6 \mathrm{hPa})$ over East Asia, associated with anomalous northeasterlies in eastern China, indicating a weakening of the East Asian summer monsoon (EASM). Associated with these circulation anomalies is a tripole pattern of precipitation changes over East Asia with an increase of $0.8-1.6 \mathrm{~mm} \mathrm{day}^{-1}$ over southern China and a decrease $\left(0.4-0.8 \mathrm{~mm} \mathrm{day}^{-1}\right)$ to the north over northern China and to the south over the SCS. Importantly, the reduced precipitation over the SCS (Fig. 9c) is associated with anomalously warm SSTs in the same region (Fig. 9a), suggesting that these regional warm SST anomalies might 
(a) DJF Simulated Rx1day change (Coupled)

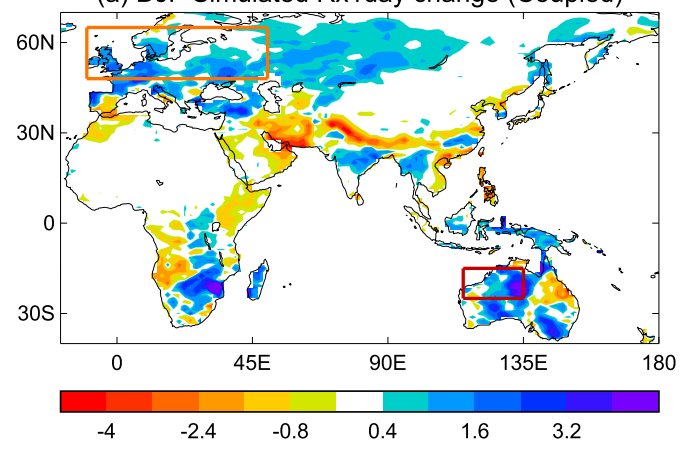

(c) DJF Simulated Rx1day change (Uncoupled)

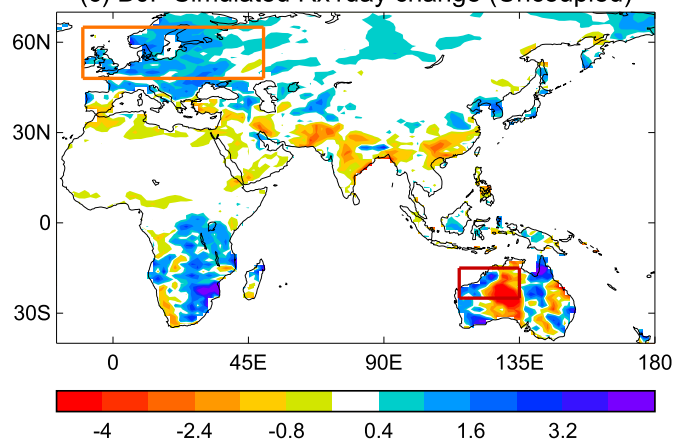

(b) JJA Simulated Rx1day change (Coupled)

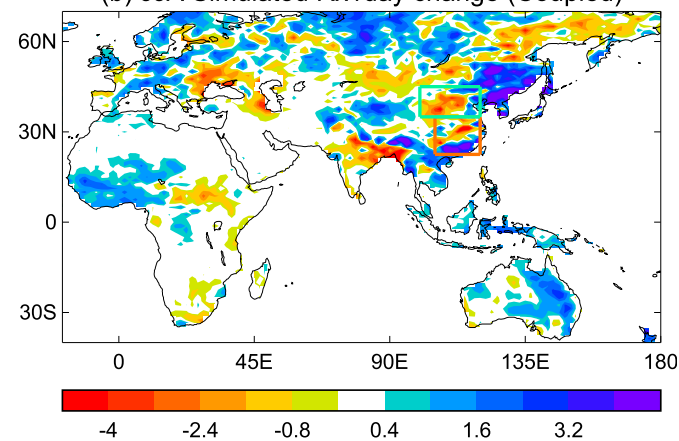

(d) JJA Simulated Rx1day change (Uncoupled)

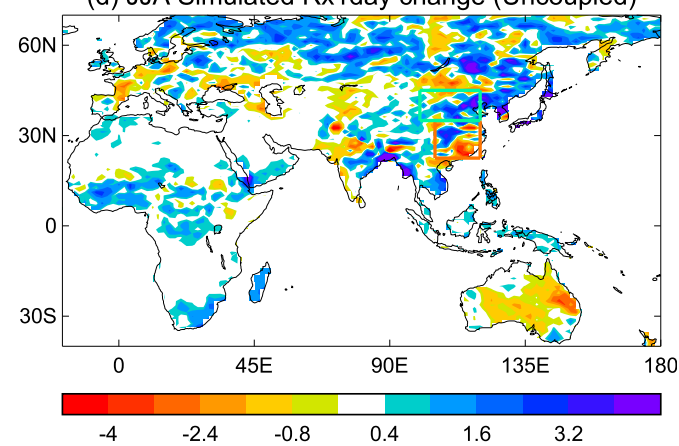

FIG. 8. Seasonal mean of monthly 1-day maximum precipitation (Rx1day) changes between PD and EP in coupled and uncoupled simulations, for (a),(b) MetUM-GOML1 model simulations (CPD - CEP) and (c),(d) uncoupled simulations (APD - AEP). Color boxes highlight regions where changes in precipitation are discussed in detail in text.

be a consequence of reduced convection. Many factors have been suggested to contribute to the decadal weakening of the EASM and associated changes in precipitation (e.g., Zhou et al. 2009), including changes in anthropogenic forcing (e.g., Song et al. 2014) and natural decadal variability (e.g., Lin et al. 2016).

The precipitation changes over East Asia in the coupled and uncoupled simulations show some contrasting features (Figs. 9f,i). These contrasting features are predominantly related to the anomalous water vapor flux convergence due to changes in circulation (dynamic transport), while the anomalous water vapor flux convergence due to changes in specific humidity (thermodynamic transport) are similar in the two models (Fig. 10). The coupled model simulates a response of increased precipitation over southern China and reduced precipitation over northern China and the SCS (Fig. 9f), which is similar to the observed pattern but only approximately half the magnitude, suggesting a role for changes in anthropogenic forcing in observed changes. The increased precipitation over southern China results from an increase in the vertically integrated water vapor transport convergence (Fig. 10a) associated with anomalous southwesterlies (Fig. 9e). In contrast, the uncoupled model simulation gives a decrease in precipitation over southern China, but an increase over the SCS (Fig. 9i). The increase of precipitation over the SCS is associated with a local anomalous cyclonic circulation and an anomalous anticyclonic circulation to the north with anomalous northeasterlies along the south coast of East Asia (Fig. 9h), leading to decrease in vertically integrated water vapor transport convergence (Fig. 10c) and therefore a decrease in precipitation over southern China (Fig. 9i). These results indicate that the uncoupled model simulates an increase in precipitation over the SCS in response to local SST warming, while observations and coupled model simulations indicate that the SST warming is associated with reduced precipitation. The results suggest that air-sea coupling over the SCS is fundamental for the attribution of local precipitation responses to anthropogenic forcing changes over China, in line with earlier studies that demonstrated the key role of air-sea coupling for simulating the climate of East Asia (Hu et al. 2012; Zhu and Shukla 2013, Lin et al. 2016).

Figure 11 illustrates changes in total surface heat flux over East Asia and the adjacent oceans in uncoupled 
(a) SST change in JJA (HadISST)

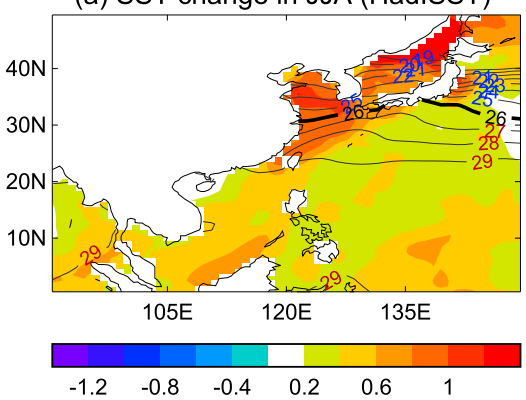

(d) JJA SST change (Coupled)

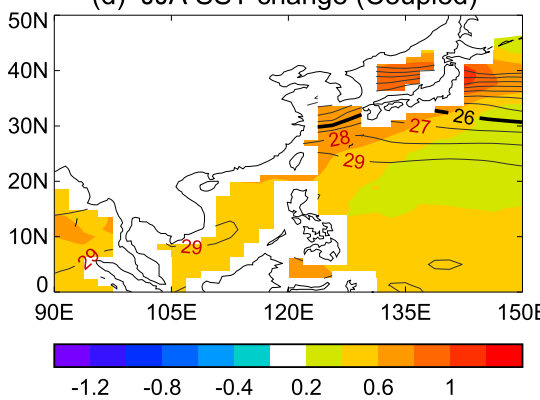

(g) JJA SST change (Uncoupled)

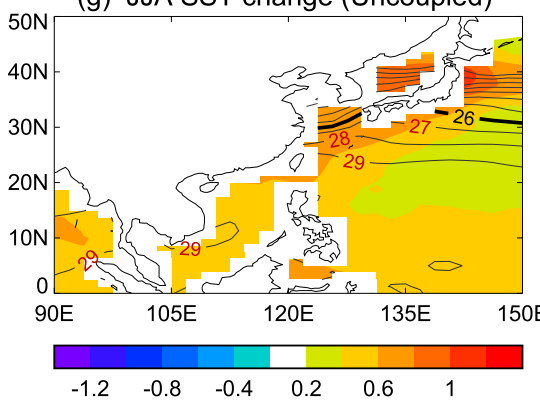

(b) SLP and $850 \mathrm{hPa}$ wind in JJA (NCEP)

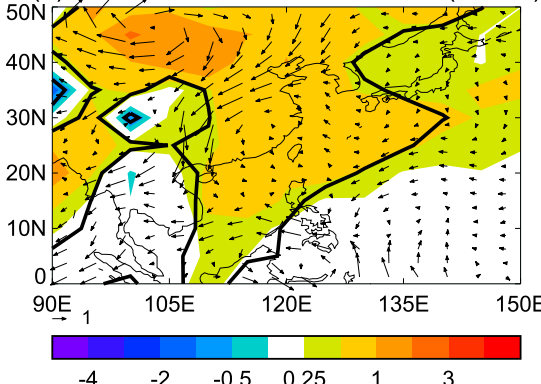

(e) JJA SLP and $850 \mathrm{hPa}$ wind (Coupled)

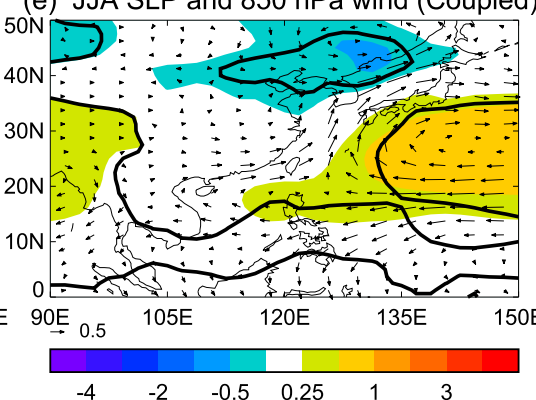

(c) Precipitation change in JJA (NOAA)

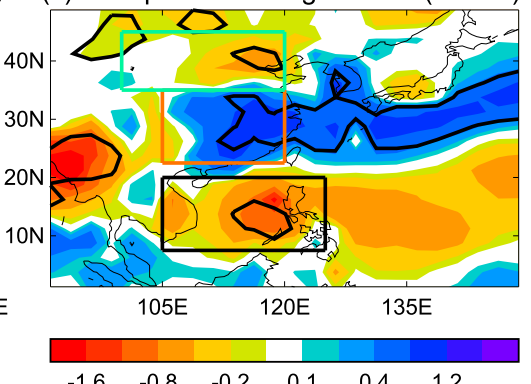

(f) JJA Precipitation change (Coupled)

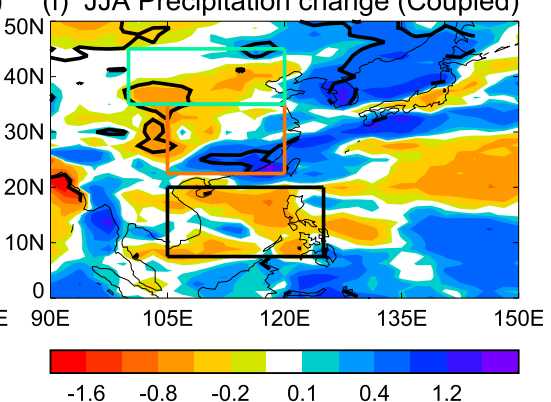

(h) JJA SLP and $850 \mathrm{hPa}$ wind (Uncoupled) (i) JJA Precipitation change (Uncoupled)

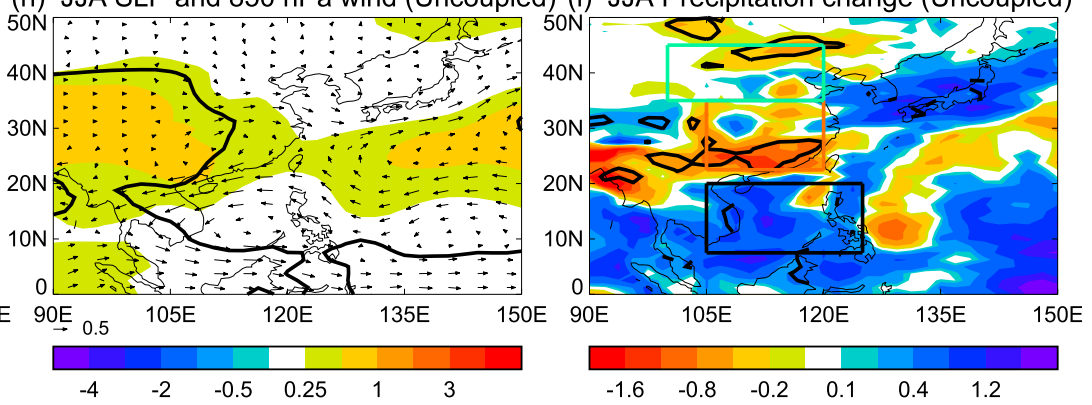

FIG. 9. Changes in (left) SST $\left({ }^{\circ} \mathrm{C}\right)$, (middle) SLP $(\mathrm{hPa})$ and $850-\mathrm{hPa}$ wind $\left(\mathrm{m} \mathrm{s}^{-1}\right)$, and (right) precipitation $\left(\mathrm{mm} \mathrm{day}^{-1}\right)$ in JJA over East Asia and adjacent oceans. Contours in left panel are the corresponding climatological SSTs for EP. Results are shown for (a)-(c) observations with SST from HadISST, SLP from HadSLP2r, 850-hPa wind from NCEP-NCAR reanalysis (Kalnay et al. 1996), and precipitation from NOAA's precipitation reconstruction (Chen et al. 2002); (d)-(f) MetUM-GOML1 model simulations (CPD - CEP); and (g)-(i) uncoupled simulations (APD - AEP). Thick lines in the middle (right) column highlight regions where the SLP (precipitation) differences are statistically significant at the $90 \%$ confidence level based on a two-tailed Student's $t$ test. Color boxes in the right panels highlight northern China, southern China, and the South China Sea.

and coupled responses, as well as the local surface energy balance over the SCS. In the coupled response, changes in total surface heat flux are positive over the SCS, which contrasts with the negative changes in the uncoupled response (Figs. 11a,b). The changes in surface energy components reveal very different heat balances (Fig. 11c). The decreases in clear-sky surface shortwave (SW) radiation are similar in the coupled and uncoupled experiments. This suggests that these decreases may arise from aerosol-radiation interactions, driven by increased aerosols precursor emissions over South and East Asia in PD relative to EP (not shown). Likewise, the increases in clear-sky surface longwave
(LW) radiation are similar in the two experiments, which suggests a dominant role for the increased greenhouse effect. The most striking difference is in the shortwave cloud radiative effect (SW CRE), which shows a positive change in the coupled simulation related to reduced convection, and a negative change in the uncoupled simulation related to enhanced convection. The coupled response indicates reduced upward latent heat flux while the uncoupled response indicates enhanced upward latent heat flux. As a result, the ocean warming between EP and PD over the SCS in the coupled simulation is the result of increased greenhouse gases and positive SW CRE due to reduced convection. 
(a) moisture covergenece (dyn) (Coupled)

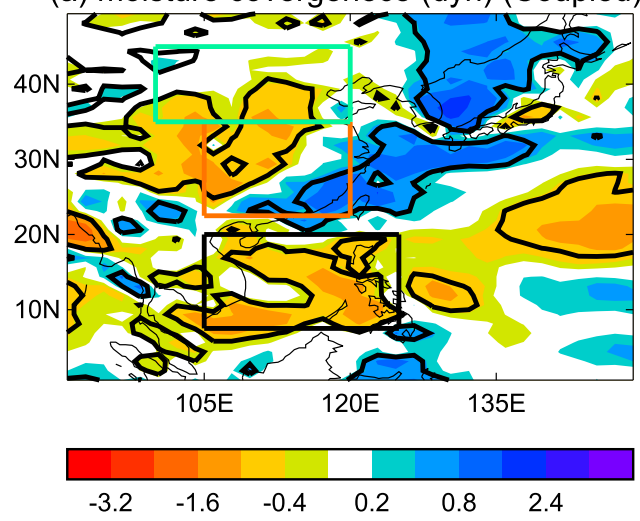

(c) moisture covergenece (dyn) (Uncoupled)

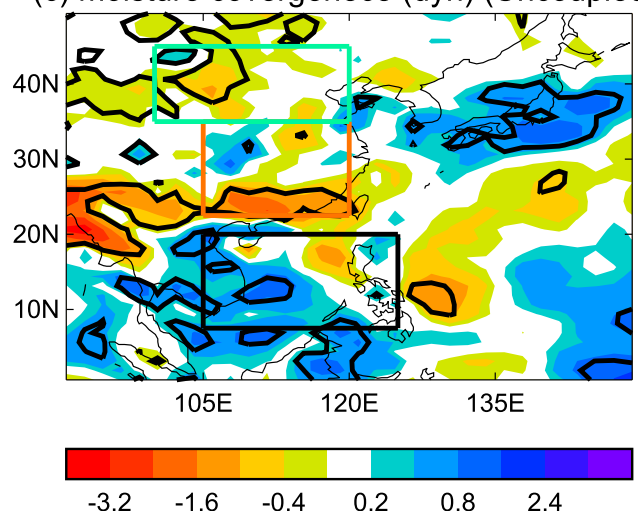

(b) moisture covergenece (thermo) (Coupled)
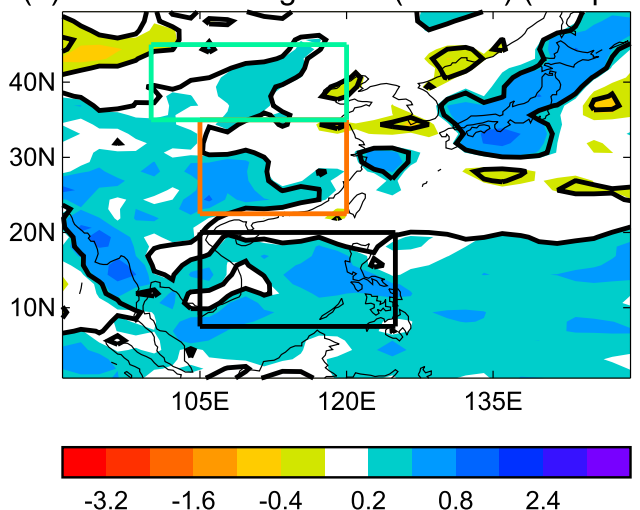

(d) moisture covergenece (thermo) (Uncoupled)

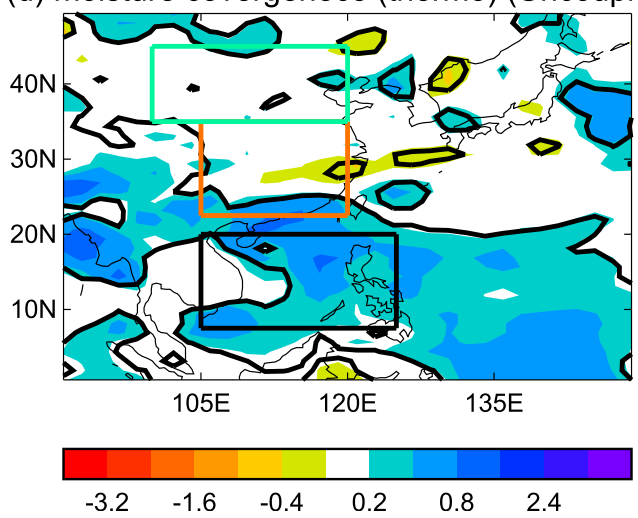

FIG. 10. Changes in vertically integrated water vapor transport convergence $\left(\mathrm{kg} \mathrm{m}^{-2} \mathrm{day}^{-1}\right)$ in JJA over East Asia and adjacent oceans, for (a), (b) MetUM-GOML1 model simulations (CPD - CEP) and (c),(d) uncoupled simulations (APD - AEP), showing transport changes due to (left) anomalous circulation (dynamical transport) and (b),(d) anomalous specific humidity (thermodynamic transport). Colored boxes highlight northern China, southern China, and the South China Sea.

In contrast, in the uncoupled simulations the SST warming over the SCS enhances the upward latent heat flux, leading to enhanced convection, reduced SW CRE, and therefore reduced SW at the surface. These contrasting responses of convection over the SCS result in different local circulation changes that are associated with the different precipitation responses over southern China.

\section{b. Australian summer monsoon response}

In this section, the processes that are responsible for contrasting precipitation responses associated with the Australian summer monsoon in the coupled and uncoupled models are investigated. Illustrated in Fig. 12 are the observed changes in DJF between EP and PD, and the simulated responses to anthropogenic forcing changes over Australia and the surrounding regions. In response to changes in anthropogenic forcings between the two periods, the coupled model overestimates SST warming over the East Indian Ocean and underestimates warming over the Maritime Continent (Figs. 2 and 12a,d). In observations, the lower tropospheric circulation changes between the two periods are characterized by anomalous northeasterlies over the MC and northwesterlies over western Australia, related to anomalously low SLP to the west of Australia and anomalously high SLP in eastern Australia (Fig. 12b), and indicating an enhanced Australian summer monsoon circulation (e.g., Rotstayn et al. 2012). Precipitation changes indicate increases $\left(\sim 0.4-0.8 \mathrm{~mm} \mathrm{day}^{-1}\right)$ over northwestern Australia and over the MC (Fig. 12c).

In the simulations, precipitation changes over northwestern Australia and the MC show a distinct contrast, with increased precipitation in the coupled simulation and decreased precipitation in the uncoupled experiment (Figs. 12f,i). The coupled model responses are similar to the observed changes but the uncoupled model produces a very different response. As for East Asia, these contrasting precipitation changes are predominantly related 
(a) surface total heat flux (Coupled) in JJA

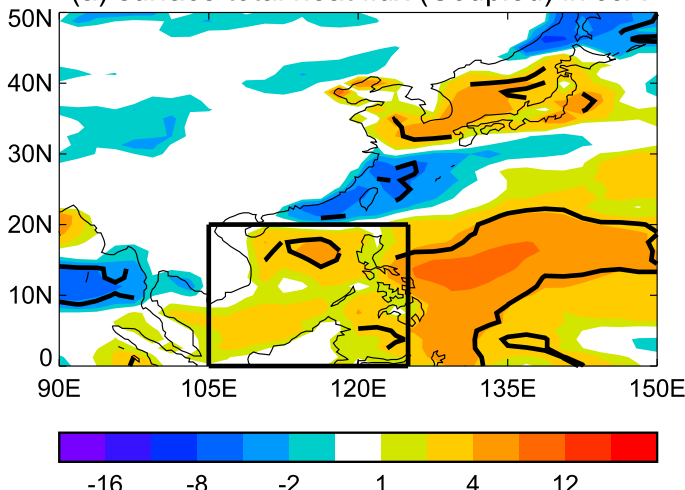

(b) surface total heat flux (Uncoupled) in JJA

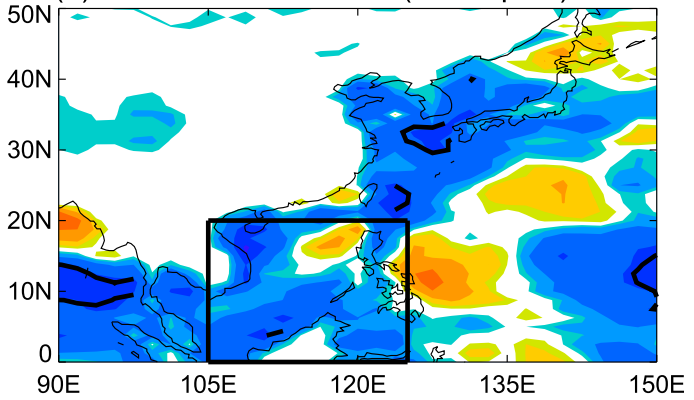

(c) Area (SCS: 0N-20N,105E-125E) averaged changes in jja

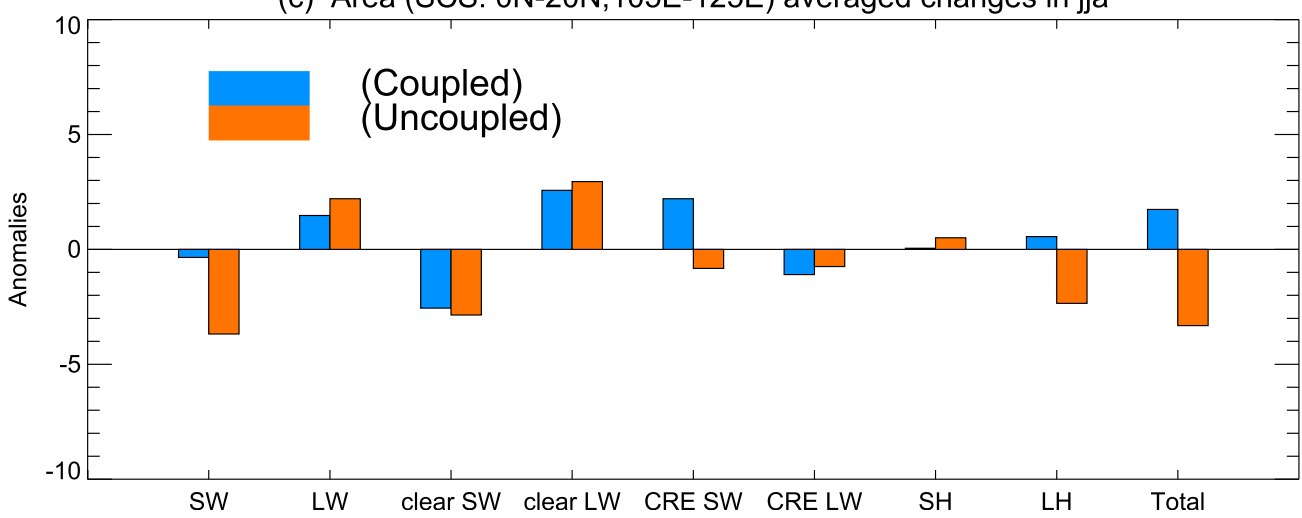

FIG. 11. (a),(b) Changes of surface total heat flux in JJA over East Asia and adjacent oceans in MetUM-GOML1 simulations (CPD - CEP) and the uncoupled simulations (APD - AEP). (c) Surface energy budgets over the South China Sea (SCS). Radiation and fluxes are in $\mathrm{W} \mathrm{m}^{-2}$ and positive values mean downward. Thick lines in (a) and (b) highlight regions where the differences are statistically significant at the $90 \%$ confidence level based on a two-tailed Student's $t$ test.

to the anomalous water vapor flux convergence due to changes in circulation (dynamic transport), while the anomalous water vapor flux convergence due to changes in specific humidity (thermodynamic transport) are similar between the two experiments (Fig. 13). In addition to contrasting responses in circulation and precipitation over northwestern Australia and the MC in coupled and uncoupled simulations, there are also distinct responses in precipitation and circulation responses over the Coral Sea (Figs. 12e,f,h,i). These results suggest a significant role for air-sea interactions over the MC and the Coral Sea for the local and regional precipitation and circulation responses.

The contrasting responses of precipitation and circulation over the MC in coupled and uncoupled models are associated with contrasting surface energy changes, illustrated in Fig. 14. Changes in surface total heat flux over the MC are negative in the coupled simulations while they are positive in the uncoupled simulations (Figs. 14a,b). The changes in surface energy components also reveal very different heat balances (Fig. 14c). The decreases in clear-sky surface SW radiation between the coupled and uncoupled experiments are again similar. As in the SCS, these decreases are likely driven by aerosol-radiation interactions associated with increased aerosol precursor emissions over South and East Asia (not shown). Likewise, the increases in clear-sky surface LW radiation between the experiments are similar, suggesting that this is predominantly due to the increased greenhouse effect. The most striking difference is SW CRE, which shows a negative change in the coupled simulation related to enhanced convection and a positive change in the uncoupled simulation related to reduced convection. The coupled response indicates an enhanced upward latent heat flux, while the uncoupled response indicates a reduced upward latent heat flux.

There are also contrasting responses in precipitation and circulation over the Coral Sea, where the coupled response indicates a weak drying and weak anomalous northeasterlies (Figs. 12e,f) but the uncoupled response indicates enhanced convection and anomalous local northwesterlies (Figs. 12h,i). These are associated with 
(a) SST change in DJF (HadlSST)

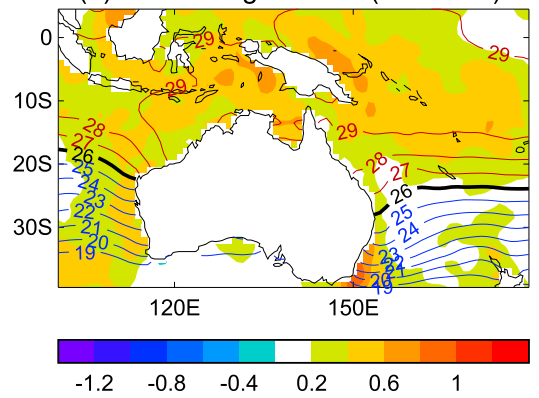

(d) DJF SST change (Coupled)

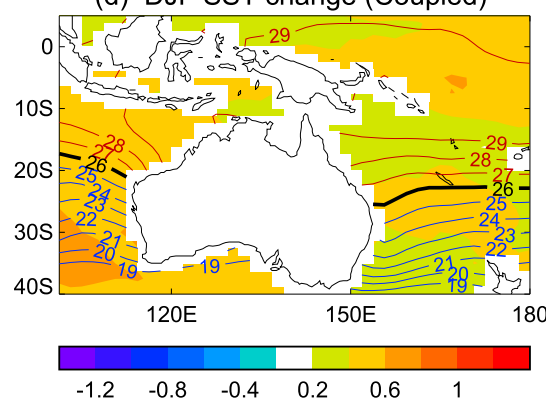

(g) DJF SST change (Uncoupled)

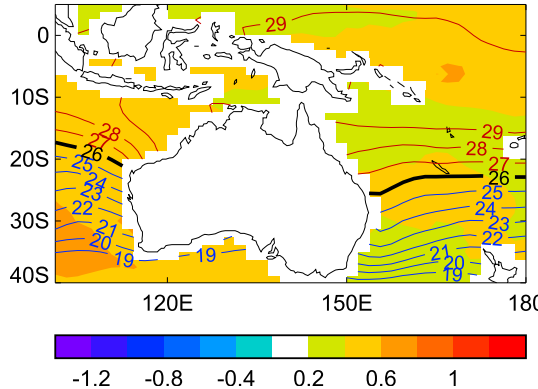

(b) SLP and $850 \mathrm{hPa}$ wind in DJF (NCEP)

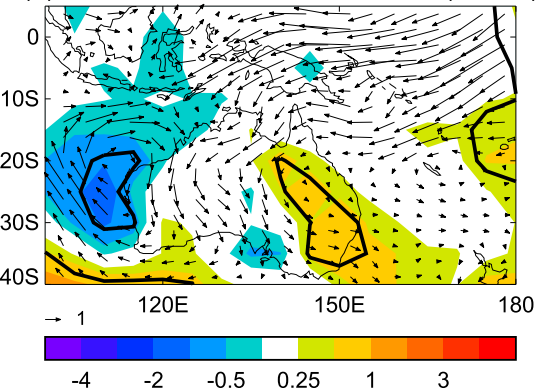

(c) Precipitation change in DJF (NOAA)

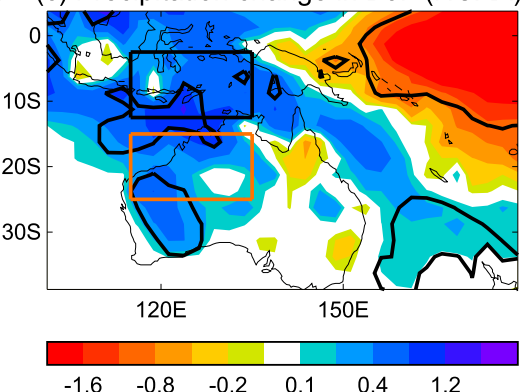

(e) DJF SLP and $850 \mathrm{hPa}$ wind (Coupled)
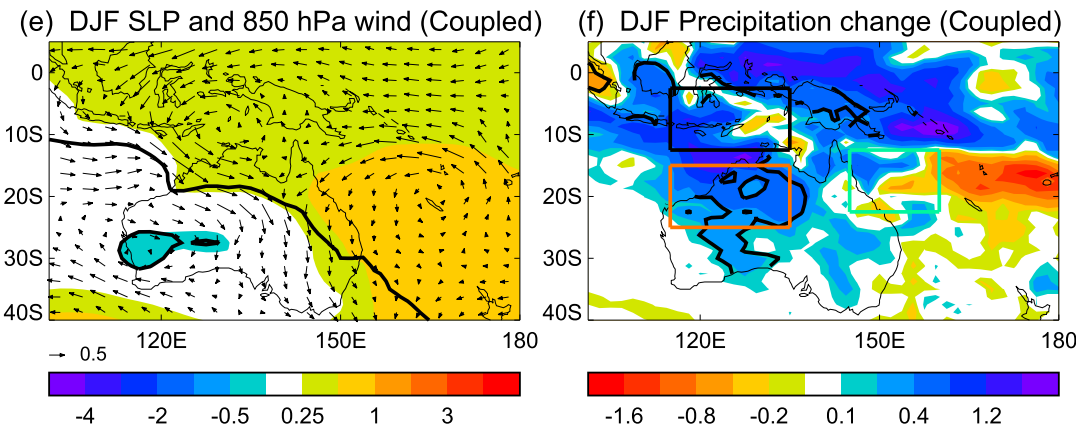

(h) DJF SLP and $850 \mathrm{hPa}$ wind (Uncoupled) (i) DJF Precipitation change (Uncoupled)
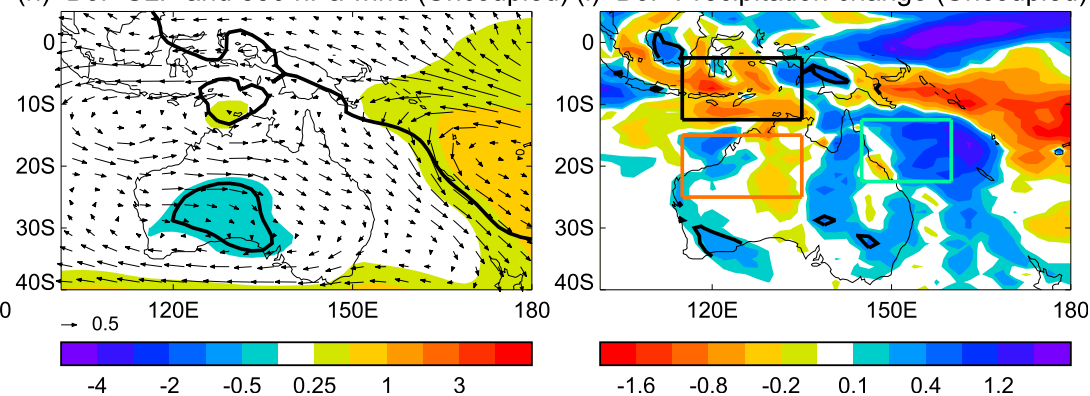

FIG. 12. Changes in (left) SST $\left({ }^{\circ} \mathrm{C}\right)$, (middle) SLP $(\mathrm{hPa})$ and $850-\mathrm{hPa}$ wind $\left(\mathrm{m} \mathrm{s}^{-1}\right)$, and (right) precipitation $\left(\mathrm{mm} \mathrm{day}^{-1}\right)$ in DJF over Australia and adjacent oceans. Contours in left panel are the corresponding climatological SSTs for EP. Results are shown for (a)-(c) observations with SST from HadISST, SLP from HadSLP2r, 850-hPa wind from NCEP-NCAR reanalysis, and precipitation from NOAA's precipitation reconstruction; (d)-(f) MetUM-GOML1 model simulations (CPD - CEP); and (g)-(i) uncoupled simulations (APD - AEP). Thick lines in the middle (right) column highlight regions where the SLP (precipitation) differences are statistically significant at the $90 \%$ confidence level based on a two-tailed Student's $t$ test. Color boxes in right panels highlight the Maritime Continent (MC), northwestern Australia, and the Coral Sea (CS).

very different changes in local surface energy balance (Fig. 14d). In the coupled simulations, it is the increased clear-sky surface longwave, associated with the increased greenhouse effect, and positive SW CRE that lead to positive total surface flux, which causes the surface warming (Fig. 12d), whereas in the uncoupled simulations it is the increased clear-sky surface longwave and reduced upward latent heat flux (related to anomalous northwesterlies, which weaken the climatological easterlies) that lead to positive total surface heat flux.

The above results demonstrate that, associated with the contrasting responses in Australian summer monsoon precipitation in the coupled and uncoupled simulations, there are very different responses in surface energy balance over both the MC and the Coral Sea. In the coupled simulations, the enhanced cross-equatorial flow associated with increased convection over the MC (Figs. 12e,f) leads to anomalous water vapor flux convergence over northwest Australia (Fig. 13a), resulting in increased precipitation (Fig. 12f). In contrast, in the uncoupled simulations, the anticyclonic circulation associated with reduced convection over the MC (Figs. 12h,i) leads to reduced water vapor flux convergence over northwest Australia (Fig. 13c) and therefore to lower precipitation (Fig. 12i). 


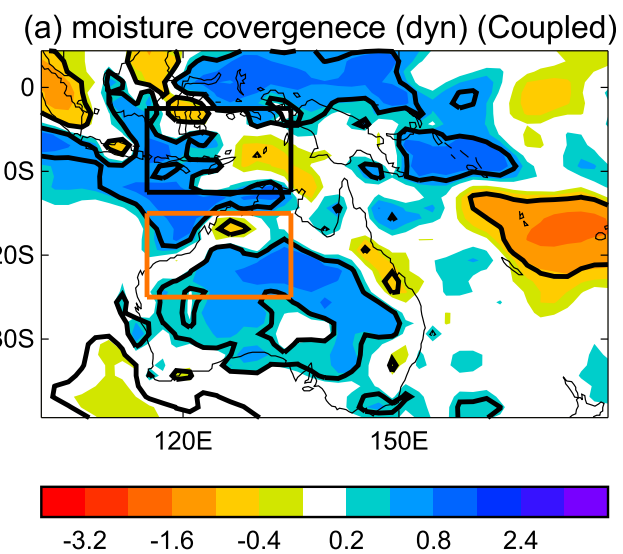

(c) moisture covergenece (dyn) (Uncoupled)

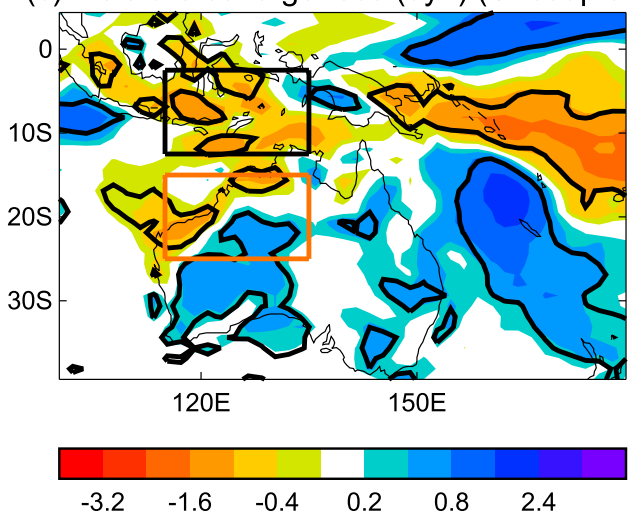

(b) moisture covergenece (thermo) (Coupled)
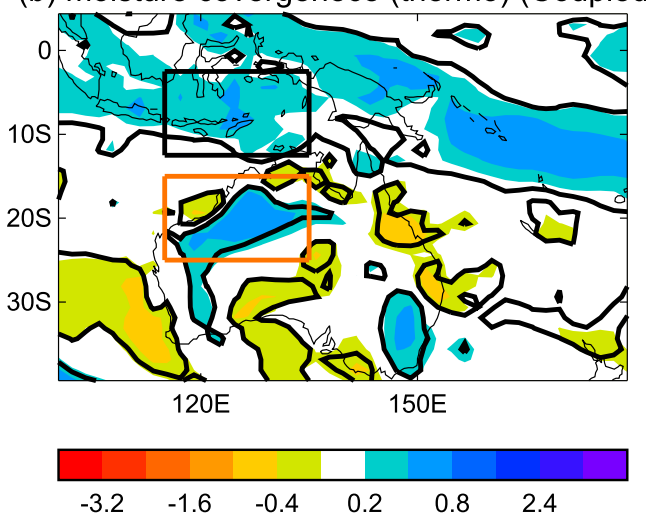

(d) moisture covergenece (thermo) (Uncoupled)

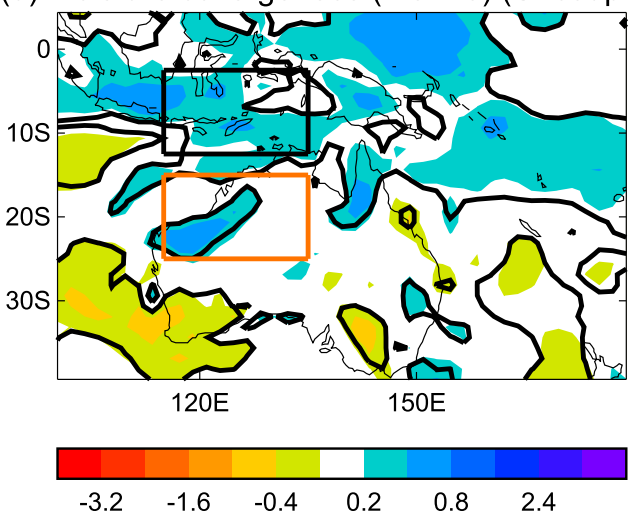

FIG. 13. Changes in vertically integrated water vapor transport convergence $\left(\mathrm{kg} \mathrm{m}^{-2} \mathrm{day}^{-1}\right)$ in DJF over Australia and adjacent oceans, from (a),(b) MetUM-GOML1 model simulations (CPD - CEP) and (c),(d) uncoupled simulations (APD - AEP), showing transport changes due to (left) anomalous circulation (dynamical transport) and (right) anomalous specific humidity (thermodynamic transport).

These results indicate the important role of air-sea interactions in adjacent oceans for the Australian summer monsoon response to changes in anthropogenic forcing. The coupled model responses are similar to the observed changes in regional precipitation, but the uncoupled model produces a very different response. These results are in line with Hendon et al. (2012), who highlighted the role of air-sea coupling for the Australian summer monsoon predictability, and $\mathrm{He}$ and Soden (2016), who indicated a sensitivity to the role of air-sea coupling in the response of Australian rainfall to changes in $\mathrm{CO}_{2}$ forcing.

\section{Conclusions}

In this paper, we have investigated the role of oceanatmosphere interactions for the attribution of forced decadal climate change in a perfect-model framework. To isolate the role of air-sea coupling, we compared attribution conclusions derived from experiments with a coupled climate model, consisting of an atmospheric model coupled to a well-resolved mixed-layer ocean, with conclusions derived from parallel experiments with the same atmospheric model forced by daily SSTs taken from the coupled model experiments. The experimental design also allows us to compare simulated changes with observed changes. The main findings are summarized as follows:

- The large-scale pattern of SST changes simulated in MetUM-GOML1 in response to changes in anthropogenic forcing is similar to observed SST changes between the two periods considered (1964-81 and 1994-2011), even though the use of a mixed-layer ocean model excludes any role for changes in ocean dynamics. This suggests that the observed decadal changes between two periods were likely to have been substantially caused by changes in anthropogenic forcing.

- Changes in surface air temperature simulated in coupled and uncoupled experiments were very similar, 
(a) surface total heat flux (Coupled) in DJF

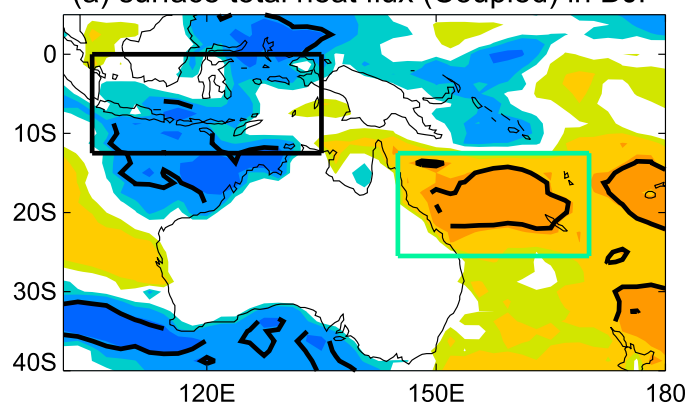

(b) surface total heat flux (Uncoupled) in DJF

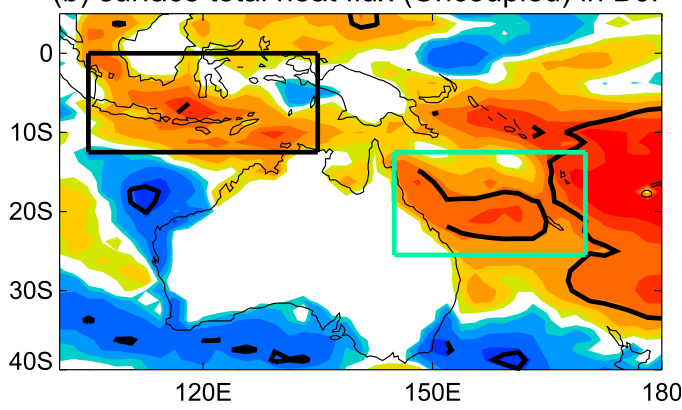

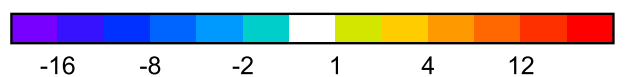

(c) Area (MC:12.5S-0S, 105E-135E) averaged changes in djf

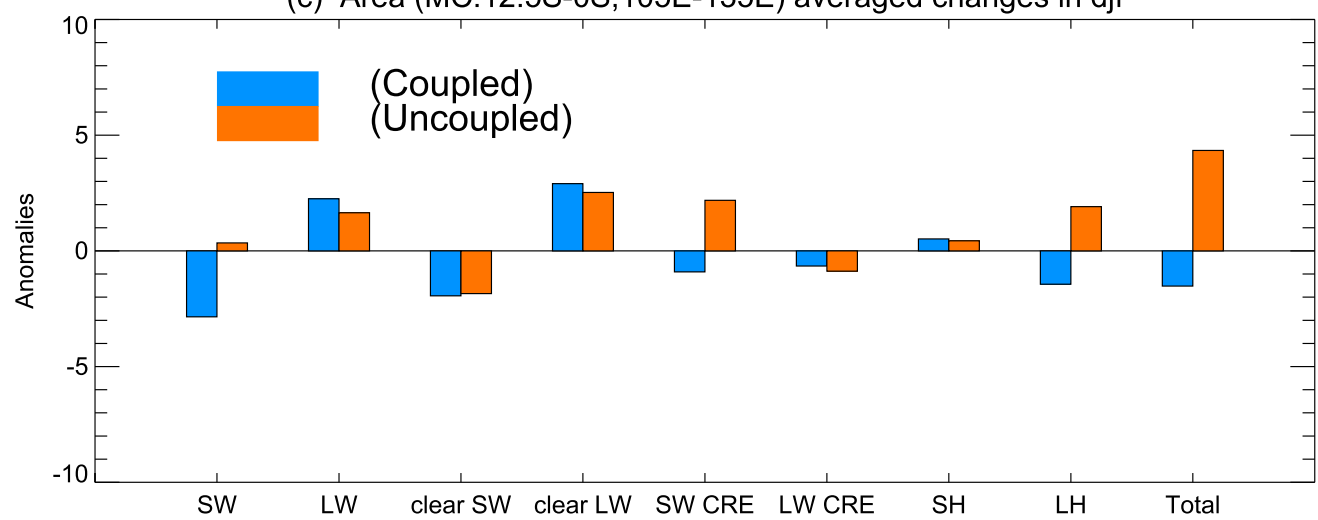

(d) Area (CS:25.5S-12.5S,145E-170E) averaged changes in djf

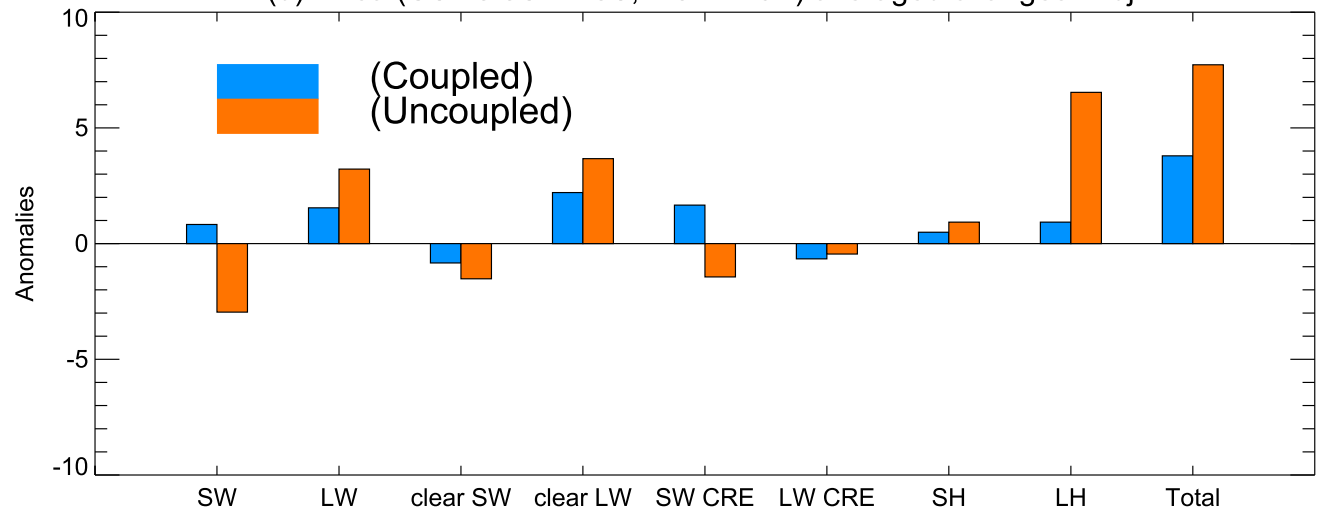

FIG. 14. (a),(b) Changes of surface total heat flux in DJF over Australia and adjacent oceans in MetUM-GOML1 simulations (CPD-CEP) and the uncoupled simulations (APD-AEP). (c),(d) Surface energy budgets over the Maritime Continent (MC) and Coral Sea (CS). Radiation and fluxes are in $\mathrm{W} \mathrm{m}^{-2}$ and positive values mean downward. Thick lines in (a) and (b) highlight regions where the differences are statistically significant at the $90 \%$ confidence level based on a two-tailed Student's $t$ test.

which suggests that attribution statements with regard to decadal SAT changes are not sensitive to the presence of air-sea coupling.

- However, mean precipitation, extreme precipitation, and mean circulation responses show large sensitivity to airsea coupling in specific regions, notably in the summer monsoon regimes of East Asia and northwest Australia.
In these regions, the coupled and uncoupled experiments produce qualitatively and quantitatively different responses. The erroneous precipitation and circulation changes found in some regions in the uncoupled (prescribed SST) experiments are due to misrepresenting the convection-SST relationship in specific regions of the tropical oceans where air-sea coupling is important. 
- The coupled simulations generally show closer agreement with observations for changes in circulation and precipitation, although the interpretation of this finding is complicated by the uncertain role of internal variability in explaining the observed changes.

AGCMs forced by prescribed SSTs, with and without anthropogenic influences, are widely used for attribution studies (e.g., Pall et al. 2011; Christidis et al. 2013, 2015; Imada et al. 2014; Kamae et al. 2014; Min et al. 2014; Shiogama et al. 2014; Rupp et al. 2015). This study, however, demonstrates that the lack of explicit atmosphere-ocean coupling may lead to erroneous attribution conclusions for circulation and precipitation changes in some regions, particularly for East Asia in boreal summer and Australia in austral summer, where monsoon circulations are the dominant source of moisture transport for precipitation. This study highlights the importance of using ocean-atmosphere coupled models for attribution of summer-mean monsoon precipitation and extreme precipitation responses over East Asia and Australia. The good agreement between observed changes and MetUM-GOML1 experiments suggests a substantial role for changes in anthropogenic forcing in observed decadal changes. It also demonstrates the potential of using a relatively simple coupled framework for attribution studies. Our results are in line with Hendon et al. (2012) and Zhu and Shukla (2013), who indicated that a lack of ocean-atmosphere coupled feedbacks is a major source of bias, resulting in an unrealistic rainfall-SST relationship over the AsianAustralian monsoon regions at interannual time scales and poor prediction skill. In summary, our results provide evidence of the importance of air-sea coupling for the attribution and projection of local precipitation and circulation changes.

It is worth of noting that this study focuses on decadal changes in seasonal mean SAT, precipitation, Rx1day, and lower tropospheric circulation. The results for other variables may differ. It is of particular interest to apply the methodology used here to single event attribution; this is the subject of further work. It is also worth to point out that this study is based on the MetUM model. The differences between coupled and uncoupled experiments in other models could be different and should be investigated.

Acknowledgments. This work was supported by EUCLEIA project funded by the European Union's Seventh Framework Programme (FP7/2007-2013) under Grant Agreement 607085 and by the UK-China Research and Innovation Partnership Fund through the Met Office Climate Science for Service Partnership (CSSP) China as part of the Newton Fund. BD, RTS, and LS are supported by the U.K. National Centre for Atmospheric Science-Climate (NCAS-Climate) at the University of Reading. NPK is supported by an Independent Research Fellowship from the U.K. Natural Environment Research Council (NE/L010976/1). The authors thank Andrew King and two anonymous reviewers for their constructive comments on the earlier version of the paper.

\section{REFERENCES}

Adler, R. F., and Coauthors, 2003: The version 2 Global Precipitation Climatology Project (GPCP) Monthly Precipitation Analysis (1979-present). J. Hydrometeor., 4, 1147-1167, doi:10.1175/1525-7541(2003)004<1147:TVGPCP > 2.0.CO;2.

Alexander, L. V., and Coauthors, 2006: Global observed changes in daily climate extremes of temperature and precipitation. J. Geophys. Res., 111, D05109, doi:10.1029/2005JD00629.

Allan, R., and T. Ansell, 2006: A new globally complete monthly historical gridded mean sea level pressure dataset (HadSLP2): 1850-2004. J. Climate, 19, 5816-5842, doi:10.1175/JCLI3937.1.

Andres, R. J., and A. D. Kasgnoc, 1998: A time-averaged inventory of subaerial volcanic sulfur emissions. J. Geophys. Res., 103, 25 251-25 261, doi:10.1029/98JD02091.

Arblaster, J. M., and G. A. Meehl, 2006: Contributions of external forcings to southern annular mode trends. J. Climate, 19, 28962905, doi:10.1175/JCLI3774.1.

Barsugli, J., and D. S. Battisti, 1998: The basic effects of atmosphereocean thermal coupling on midlatitude variability. J. Atmos. Sci., 55, 477-493, doi:10.1175/1520-0469(1998)055<0477: TBEOAO $>2.0 . \mathrm{CO} ; 2$.

Black, M. T., D. J. Karoly, and A. D. King, 2015: The contribution of anthropogenic forcing to the Adelaide and Melbourne heatwaves of January 2014 [in "Explaining Extreme Events of 2014 from a Climate Perspective"]. Bull. Amer. Meteor. Soc., 96, S144-S148, doi:10.1175/BAMS-D-15-00097.1.

Boer, G. J., and Coauthors, 2016: The Decadal Climate Prediction Project (DCPP) contribution to CMIP6. Geosci. Model Dev., 9, 3751-3777, doi:10.5194/gmd-9-3751-2016.

Bindoff, N. L., and Coauthors, 2013: Detection and attribution of climate change: From global to regional. Climate Change 2013: The Physical Science Basis, T. F. Stocker et al., Eds., Cambridge University Press, 867-952.

Chen, M., P. Xie, J. E. Janowiak, and P. A. Arkin, 2002: Global land precipitation: A 50-yr monthly analysis based on gauge observations. J. Hydrometeor., 3, 249-266, doi:10.1175/ 1525-7541(2002)003<0249:GLPAYM > 2.0.CO;2.

Chen, W., and R. Lu, 2014: A decadal shift of summer surface air temperature over the northeast Asia around the mid-1990s. Adv. Atmos. Sci., 31, 735-742, doi:10.1007/s00376-013-3154-4.

Christidis, N., P. A. Stott, F. W. Zwiers, H. Shiogama, and T. Nozawa, 2012: The contribution of anthropogenic forcings to regional changes in temperature during the last decade. Climate Dyn., 39, 1259-1274, doi:10.1007/s00382-011-1184-0.

- _ - A. Scaife, A. Arribas, G. S. Jones, D. Copsey, J. R. Knight, and W. J. Tennant, 2013: A new HadGEM3-A-based system for attribution of weather and climate-related extreme events. J. Climate, 26, 2756-2783, doi:10.1175/JCLI-D-12-00169.1.

, G. S. Jones, and P. A. Stott, 2015: Dramatically increasing chance of extremely hot summers since the 2003 European heatwave. Nat. Climate Change, 5, 46-50, doi:10.1038/nclimate2468. 
Dall'Amico, M., L. Gray, K. Rosenlof, A. Scaife, K. Shine, and P. Stott, 2010: Stratospheric temperature trends: Impact of ozone variability and the QBO. Climate Dyn., 34, 381-398, doi:10.1007/s00382-009-0604-X.

DeMott, C. A., N. P. Klingaman, and S. J. Woolnough, 2015: Atmosphere-ocean coupled processes in the Madden-Julian oscillation. Rev. Geophys., 53, 1099-1154, doi:10.1002/2014RG000478.

Donat, M. G., and Coauthors, 2013: Updated analyses of temperature and precipitation extreme indices since the beginning of the twentieth century: The HadEX2 dataset. J. Geophys. Res. Atmos., 118, 2098-2118, doi:10.1002/jgrd.50150.

Dong, B.-W., R. T. Sutton, W. Chen, X.-D. Liu, R.-Y. Lu, and Y. Sun, 2016: Abrupt summer warming and changes in temperature extremes over Northeast Asia since the mid-1990s: Drivers and physical processes. Adv. Atmos. Sci., 33, 10051023, doi:10.1007/s00376-016-5247-3.

,-- , and L. Shaffrey, 2017: Understanding the rapid summer warming and changes in temperature extremes since the mid1990s over western Europe. Climate Dyn., 48, 1537-1554, doi:10.1007/s00382-016-3158-8.

Fischer, E. M., and R. Knutti, 2014: Detection of spatially aggregated changes in temperature and precipitation extremes. Geophys. Res. Lett., 41, 547-554, doi:10.1002/2013GL058499.

$\longrightarrow$, and - 2015: Anthropogenic contribution to global occurrence of heavy-precipitation and high-temperature extremes. Nat. Climate Change, 5, 560-564, doi:10.1038/nclimate2617.

Fyfe, J., G. Boer, and G. Flato, 1999: The Arctic and Antarctic oscillations and their projected changes under global warming. Geophys. Res. Lett., 26, 1601-1604, doi:10.1029/1999GL900317.

Gillett, N. P., and D. W. J. Thompson, 2003: Simulation of recent Southern Hemisphere climate change. Science, 302, 273-275, doi:10.1126/science.1087440.

Ham, S., S.-Y. Hong, and S. Park, 2014: A study on air-sea interaction on the simulated seasonal climate in an oceanatmosphere coupled model. Climate Dyn., 42, 1175-1187, doi:10.1007/s00382-013-1847-0.

Hansen, G., and D. Stone, 2016: Assessing the observed impact of anthropogenic climate change. Nat. Climate Change, 6, 532537, doi:10.1038/nclimate2896.

Hansen, J., R. Ruedy, M. Sato, and K. Lo, 2010: Global surface temperature change. Rev. Geophys., 48, RG4004, doi:10.1029/ 2010RG000345.

Harris, I., P. D. Jones, T. J. Osborn, and D. H. Lister, 2014: Updated high-resolution grids of monthly climatic observations-The CRU TS3.10 dataset. Int. J. Climatol., 34, 623-642, doi:10.1002/ joc.3711.

He, J., and B. Soden, 2016: Does the lack of coupling in SST-forced atmosphere-only models limit their usefulness for climate change studies? J. Climate, 29, 4317-4325, doi:10.1175/ JCLI-D-14-00597.1.

Hegerl, G. C., and F. Zwiers, 2011: Use of models in detection and attribution of climate change. Wiley Interdiscip. Rev.: Climatic Change, 2, 570-591, doi:10.1002/wcc.121.

—_ and Coauthors, 2007: Understanding and attributing climate change. Climate Change 2007: The Physical Science Basis, S. Solomon et al., Eds., Cambridge University Press, 663-745.

Hendon, H. H., E.-P. Lim, and G. Liu, 2012: The role of air-sea interaction for prediction of Australian summer monsoon rainfall. J. Climate, 25, 1278-1290, doi:10.1175/JCLI-D-11-00125.1.

Hewitt, H. T., D. Copsey, I. D. Culverwell, C. M. Harris, R. S. R. Hill, A. B. Keen, A. J. McLaren, and E. C. Hunke, 2011: Design and implementation of the infrastructure of HadGEM3: The next-generation Met Office climate modelling system. Geosci. Model Dev., 4, 223-253, doi:10.5194/gmd-4-223-2011.

Hirons, L. C., N. P. Klingaman, and S. J. Woolnough, 2015: MetUM-GOML: A near-globally coupled atmosphere-oceanmixed-layer model. Geosci. Model Dev., 8, 363-379, doi:10.5194/ gmd-8-363-2015.

$\mathrm{Hu}$, Y., Z. Zhong, X. Liu, and Y. Zhu, 2012: Influence of air-sea interaction on the simulation of the East Asian summer monsoon: A case study. Dyn. Atmos. Oceans, 53-54, 1-16, doi:10.1016/j.dynatmoce.2011.12.001.

Imada, Y., H. Shiogama, M. Watanabe, M. Mori, M. Ishii, and M. Kimoto, 2014: The contribution of anthropogenic forcing to the Japanese heat waves of 2013 [in "Explaining Extreme Events of 2014 from a Climate Perspective"]. Bull. Amer. Meteor. Soc., 95, S48-S51.

Jones, G. S., P. A. Stott, and N. Christidis, 2013: Attribution of observed historical near surface temperature variations to anthropogenic and natural causes using CMIP5 simulations. J. Geophys. Res. Atmos., 118, 4001-4024, doi:10.1002/jgrd.50239.

Kalnay, E., and Coauthors, 1996: The NCEP/NCAR 40-Year Reanalysis Project. Bull. Amer. Meteor. Soc., 77, 437-471, doi:10.1175/1520-0477(1996)077<0437:TNYRP>2.0.CO;2.

Kamae, Y., H. Shiogama, M. Watanabe, and M. Kimoto, 2014: Attributing the increase in Northern Hemisphere hot summers since the late 20th century. Geophys. Res. Lett., 41, 51925199, doi:10.1002/2014GL061062.

King, A. D., M. T. Black, D. J. Karoly, and M. G. Donat, 2015a: Increased likelihood of Brisbane G20 heat event due to anthropogenic climate change [in "Explaining Extreme Events of 2014 from a Climate Perspective"']. Bull. Amer. Meteor. Soc., 96, S141-S144, doi:10.1175/BAMS-D-15-00098.1.

- G. J. van Oldenborgh, D. J. Karoly, S. C. Lewis, and H. Cullen, 2015b: Attribution of the record high central England temperature of 2014 to anthropogenic influences. Environ. Res. Lett., 10, 054002, doi:10.1088/1748-9326/10/5/054002.

—, M. T. Black, S.-K. Min, E. M. Fischer, D. M. Mitchell, L. J. Harrington, and S. E. Perkins-Kirkpatrick, 2016: Emergence of heat extremes attributable to anthropogenic influences. Geophys. Res. Lett., 43, 3438-3443, doi:10.1002/2015GL067448.

Knutson, T. R., F. Zeng, and A. T. Wittenberg, 2013: Multimodel assessment of regional surface temperature trends: CMIP3 and CMIP5 twentieth-century simulations. J. Climate, 26, 8709-8743, doi:10.1175/JCLI-D-12-00567.1.

Lamarque, J. F., and Coauthors, 2010: Historical (1850-2000) gridded anthropogenic and biomass burning emissions of reactive gases and aerosols: Methodology and application. Atmos. Chem. Phys., 10, 7017-7039, doi:10.5194/acp-10-7017-2010.

_- and Coauthors, 2011: Global and regional evolution of shortlived radiatively-active gases and aerosols in the representative concentration pathways. Climatic Change, 109, 191-212, doi:10.1007/s10584-011-0155-0.

Large, W., J. McWilliams, and S. Doney, 1994: Oceanic vertical mixing: A review and a model with a nonlocal boundary layer parameterization. Rev. Geophys., 32, 363-403, doi:10.1029/94RG01872.

Legates, D. R., and C. J. Willmott, 1990a: Mean seasonal and spatial variability in global surface air temperature. Theor. Appl. Climatol., 41, 11-21, doi:10.1007/BF00866198.

$\ldots$, and 1 1990b: Mean seasonal and spatial variability in gauge-corrected, global precipitation. Int. J. Climatol., 10, 111-127, doi:10.1002/joc.3370100202.

Lewis, S. C., and D. J. Karoly, 2013: Anthropogenic contributions to Australia's record summer temperatures of 2013. Geophys. Res. Lett., 40, 3705-3709, doi:10.1002/grl.50673. 
Lin, R., J. Zhu, and F. Zheng, 2016: Decadal shifts of East Asian summer monsoon in a climate model free of explicit GHGs and aerosols. Sci. Rep., 6, 38546, doi:10.1038/srep38546.

McGregor, S., A. Timmermann, M. F. Stuecker, M. H. England, M. Merrifield, F.-F. Jin, and Y. Chikamoto, 2014: Recent Walker circulation strengthening and Pacific cooling amplified by Atlantic warming. Nat. Climate Change, 4, 888-892, doi:10.1038/nclimate2330.

Min, S.-K., Y.-H. Kim, M.-K. Kim, and C. Park, 2014: Assessing human contribution to the summer 2013 Korean heat wave [in "Explaining Extreme Events of 2013 from a Climate Perspective"]. Bull. Amer. Meteor. Soc., 95, S48-S51.

Morak, S., G. C. Hegerl, and N. Christidis, 2013: Detectable changes in the frequency of temperature extremes. J. Climate, 26, 1561-1574, doi:10.1175/JCLI-D-11-00678.1.

National Academies of Sciences, Engineering, and Medicine (NAS), 2016: Attribution of Extreme Weather Events in the Context of Climate Change. National Academies Press, 186 pp., doi:10.17226/21852.

Pall, P., and Coauthors, 2011: Anthropogenic greenhouse gas contribution to flood risk in England and Wales in autumn 2000. Nature, 470, 382-385, doi:10.1038/nature09762.

Perkins, S. E., 2015: A review on the scientific understanding of heatwaves-Their measurement, driving mechanisms, and changes at the global scale. Atmos. Res., 164-165, 242-267, doi:10.1016/j.atmosres.2015.05.014.

_ _ L. V. Alexander, and J. R. Nairn, 2012: Increasing frequency, intensity and duration of observed global heatwaves and warm spells. Geophys. Res. Lett., 39, L20714, doi:10.1029/ 2012 GL053361.

Rayner, N. A. D. E. Parker, E. B. Horton, C. K. Folland, L. V. Alexander, D. P. Rowell, E. C. Kent, and A. Kaplan, 2003: Global analyses of SST, sea ice and night marine air temperature since the late nineteenth century. J. Geophys. Res., 108, 4407, doi:10.1029/2002JD002670.

Ringer, M. A., and Coauthors, 2006: The physical properties of the atmosphere in the new Hadley Centre Global Environmental Model (HadGEM1). Part II: Aspects of variability and regional climate. J. Climate, 19, 1302-1326, doi:10.1175/ JCLI3713.1.

Robson, J., R. Sutton, K. Lohmann, D. Smith, and M. D. Palmer, 2012: Causes of the rapid warming of the North Atlantic Ocean in the mid-1990s. J. Climate, 25, 4116-4134, doi:10.1175/JCLI-D-11-00443.1.

Rotstayn, L., and Coauthors, 2012: Aerosol- and greenhouse gasinduced changes in summer rainfall and circulation in the Australasian region: A study using single-forcing climate simulations. Atmos. Chem. Phys., 12, 6377-6404, doi:10.5194/ acp-12-6377-2012.

Rupp, D. E., S. Li, N. Massey, S. N. Sparrow, P. W. Mote, and M. Allen, 2015: Anthropogenic influence on the changing likelihood of an exceptionally warm summer in Texas, 2011. Geophys. Res. Lett., 42, 2392-2400, doi:10.1002/ 2014GL062683.

Sarojini, B. B., P. A. Stott, and E. Black, 2016: Detection and attribution of human influence on regional precipitation. Nat. Climate Change, 6, 669-675, doi:10.1038/nclimate2976.

Schaller, N., and Coauthors, 2016: Human influence on climate in the 2014 southern England winter floods and their impacts. Nat. Climate Change, 6, 627-634, doi:10.1038/nclimate2927.

Seneviratne, S. I., 2012: Historical drought trends revisited. Nature, 491, 338-339, doi:10.1038/491338a.
Shindell, D. T., and G. A. Schmidt, 2004: Southern Hemisphere climate response to ozone changes and greenhouse gas increases. Geophys. Res. Lett., 31, L18209, doi:10.1029/ 2004GL020724.

Shiogama, H., M. Watanabe, Y. Imada, M. Mori, Y. Kamae, M. Ishii, and M. Kimoto, 2014: Attribution of the June-July 2013 heat wave in the southwestern United States. SOLA, 10, 122-126, doi:10.2151/sola.2014-025.

Smith, D. M., and J. M. Murphy, 2007: An objective ocean temperature and salinity analysis using covariances from a global climate model. J. Geophys. Res., 112, C02022, doi:10.1029/ $2005 J C 003172$.

Song, F., T. Zhou, and Y. Qian, 2014: Responses of East Asian summer monsoon to natural and anthropogenic forcings in the 17 latest CMIP5 models. Geophys. Res. Lett., 41, 596-603, doi:10.1002/2013GL058705.

Sperber, K. R., H. Annamalai, I. S. Kang, A. Kitoh, A. Moise, A. Turner, B. Wang, and T. Zhou, 2013: The Asian summer monsoon: An intercomparison of CMIP5 vs. CMIP3 simulations of the late 20th century. Climate Dyn., 41, 2711-2744, doi:10.1007/s00382-012-1607-6.

Stott, P. A., N. P. Gillett, G. C. Hegerl, D. J. Karoly, D. A. Stone, X. Zhang, and F. Zwiers, 2010: Detection and attribution of climate change: A regional perspective. Wiley Interdiscip. Rev.: Climate Change, 1, 192-211, doi:10.1002/wcc.34.

— , and Coauthors, 2016: Attribution of extreme weather and climate-related events. Wiley Interdiscip. Rev.: Climate Change, 7, 23-41, doi:10.1002/wcc.380.

Sun, Y., X. Zhang, F. W. Zwiers, L. Song, H. Wan, T. Hu, H. Yin, and G. Ren, 2014: Rapid increase in the risk of extreme summer heat in eastern China. Nat. Climate Change, 4, 10821085, doi:10.1038/nclimate2410.

Valcke, S., A. Caubel, D. Declat, and L. Terray, 2003: OASIS3 Ocean Atmosphere Sea Ice Soil user's guide. Tech. Rep. TR/ CMGC/03/69, CERFACS, 73 pp.

van Oldenborgh, G. J., S. Drijfhout, A. van Ulden, R. Haarsma, A. Sterl, C. Severijns, W. Hazeleger, and H. Dijkstra, 2009: Western Europe is warming much faster than expected. Climate Past, 5, 1-12, doi:10.5194/cp-5-1-2009.

Walters, D. N., and Coauthors, 2011: The Met Office Unified Model Global Atmosphere 3.0/3.1 and JULES Global Land 3.0/3.1 configurations. Geosci. Model Dev., 4, 919-941, doi:10.5194/gmd-4-919-2011.

Wang, B., Q. Ding, X. Fu, I.-S. Kang, K. Jin, J. Shukla, and F. Doblas-Reyes, 2005: Fundamental challenge in simulation and prediction of summer monsoon rainfall. Geophys. Res. Lett., 32, L15711, doi:10.1029/2005GL022734.

Wang, C., L. Zhang, S.-K. Lee, L. Wu, and C. R. Mechoso, 2014: A global perspective on CMIP5 climate model biases. Nat. Climate Change, 4, 201-205, doi:10.1038/nclimate2118.

Weaver, S. J., A. Kumar, and M. Chen, 2014: Recent increases in extreme temperature occurrence over land. Geophys. Res. Lett., 41, 4669-4675, doi:10.1002/2014GL060300.

Wen, H. Q., X. Zhang, Y. Xu, and B. Wang, 2013: Detecting human influence on extreme temperatures in China. Geophys. Res. Lett., 40, 1171-1176, doi:10.1002/grl.50285.

Zhou, T., D. Gong, J. Li, and B. Li, 2009: Detecting and understanding the multi-decadal variability of the East Asian summer monsoon-Recent progress and state of affairs. $M e$ teor. Z., 18, 455-467, doi:10.1127/0941-2948/2009/0396.

Zhu, J., and J. Shukla, 2013: The role of air-sea coupling in seasonal prediction of Asia-Pacific summer monsoon rainfall. J. Climate, 26, 5689-5697, doi:10.1175/JCLI-D-13-00190.1. 